\title{
Preparation of Metalloporphyrin-Bound Superparamagnetic Silica Particles via "Click” Reaction
}

\author{
Javoris V. Hollingsworth ${ }^{\dagger, \perp,{ }^{*}}$, N. V. S. Dinesh K. Bhupathiraju ${ }^{\dagger}$, Jirun Sun ${ }^{\ddagger}$, Eric Lochner ${ }^{\S}$, \\ M. Graça H. Vicente ${ }^{\dagger}$, and Paul S. Russo ${ }^{\dagger, \|, *}$ \\ tDepartment of Chemistry and Macromolecular Studies Group, Louisiana State University, Baton \\ Rouge, Louisiana 70803, United States \\ $\neq$ Dr. Anthony Volpe Research Center, American Dental Association Foundation, 100 Bureau \\ Drive, Stop 8546, Gaithersburg, Maryland 20899, United States \\ §Department of Physics, Florida State University, Tallahassee, Florida 32306, United States \\ "School of Materials Science and Engineering, School of Chemistry and Biochemistry and \\ Georgia Tech Polymer Network, Georgia Institute of Technology, Atlanta, Georgia 30332, United \\ States \\ ${ }^{\perp}$ Department of Chemistry \& Physics, University of St. Thomas, Houston, Texas 77006, United \\ States
}

\section{Abstract}

A facile approach using click chemistry is demonstrated for immobilization of metalloporphyrins onto the surface of silica-coated iron oxide particles. Oleic-acid stabilized iron oxide nanocrystals were prepared by thermal decomposition of iron(III) acetylacetonate. Their crystallinity, morphology, and superparamagnetism were determined using X-ray diffraction, transmission electron microscopy, and a superconducting quantum interference device. Monodisperse coreshell particles were produced in the silica-coating of iron oxide via microemulsion synthesis. Surface modification of these particles was performed in two steps, which included the reaction of silica-coated iron oxide particles with 3-bromopropyltrichlorosilane, followed by azidofunctionalization with sodium azide. Monoalkylated porphyrins were prepared using the Williamson ether synthesis of commercially available tetra(4-hydroxyphenyl) porphyrin with propargyl bromide in the presence of a base. ${ }^{1} \mathrm{H}$ NMR and matrix-assisted laser desorption ionization confirmed the identity of the compounds. The prepared monoalkyne porphyrins were zinc-metalated prior to their introduction to azide-functionalized, silica-coated iron oxide particles in the click reaction. X-ray photoelectron spectroscopy, thermogravimetric analysis, and Fourier transform infrared spectroscopy were used to characterize the surface chemistry after each step in

*Corresponding Authors. ; Email: hollinjv@stthom.edu, ; Email: paul.russo@mse.gatech.edu ASSOCIATED CONTENT

Supporting Information

The Supporting Information is available free of charge on the ACS Publications website at DOI: 10.1021/acsami.5b10034.

${ }^{13} \mathrm{C}-\mathrm{NMR}$ and ${ }^{1} \mathrm{H}-\mathrm{NMR}$ spectra of compound 3; electron diffraction pattern for silica-Fe3 $\mathrm{O}_{4}$-click-ZnTPP nanoparticles. (PDF) 
the reaction. In addition, particle size was determined using dynamic light scattering and microscopy. The presented methodology is versatile and can be extended to other photoreactive systems, such as phthalocyanines and boron-dipyrromethane, which may lead to new materials for optical, photonic, and biological applications.

\section{Graphical Abstract}

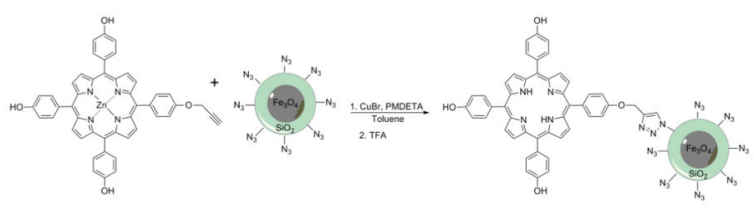

\section{Keywords}

metalloporphyrin; silica; iron oxide; superparamagnetic; click chemistry

\section{INTRODUCTION}

Free-base and metalloporphyrins are well known for exhibiting extraordinary photo- and electrochemical properties. As noted elsewhere, ${ }^{1}$ these properties are useful in applications ranging from photodynamic therapy ${ }^{2}$ to catalysis. ${ }^{3}-{ }^{5}$ However, inherent drawbacks of these homogeneous systems involve their susceptibility to oxidative self-destruction and aggregation. ${ }^{6}$ These phenomena occur when the macrocycles spontaneously self-assemble through noncovalent interactions, forming oligomers and/or dimers. ${ }^{7}$ Using nanotechnologybased strategies, such issues can be overcome via immobilization of porphyrins onto supports. In previous studies, this approach ${ }^{8}$ was demonstrated by loading or chemically binding metalloporphyrins onto various types of scaffolds, including polymers, ${ }^{9}$ carbon nanotubes, ${ }^{10}$ zeolites, ${ }^{11},{ }^{12}$ and clays. ${ }^{13},{ }^{14}$

According to recent observations, 56 in comparison to nonsupported metalloporphyrins, metalloporphyrin-bound composites display increased stability and selectivity, as well as improved recovery. Generally, inorganic materials are the solid support of choice, due to their robustness and efficiency in inhibiting deactivation of photoactive compounds.

Inorganic supports also possess higher mechanical strength and minimal swelling in aqueous or organic solvents, which prevents metalloporphyrins from leaching. ${ }^{6}$ In particular, silica is often used as a result of its excellent stability and versatility for covalent attachment of various functional groups.

Over the past decade, the combination of organic catalysts attached to magnetic composite particles has shown much promise for useful applications, providing high catalytic activity, easy magnetic recovery ${ }^{15}$ and recyclability. ${ }^{16 \_18}$ These desirable characteristics also make the catalysts more cost-effective, which broadens their practical use. In a recent report, Saeedi and co-workers demonstrated ${ }^{4}$ the highly efficient oxidative properties, facile magnetic recovery and reuse of tetraphenylporphyrinatomanganese(III) chloride tethered to imidazole-bound magnetic silica-coated iron oxide $\left(\mathrm{Fe}_{3} \mathrm{O}_{4}\right)$ particles via axial ligation. Liu et al. ${ }^{19}$ describe the synthesis of magnetic nanocomposite-bound metalloporphyrins via 
silanation between 3-aminopropyltriethoxysilane-derivatized metalloporphyrin carboxylic acids and silica-coated $\mathrm{Fe}_{3} \mathrm{O}_{4}$ nanoparticles. According to their study, in relation to other immobilization methods, the reaction was easier to perform and yielded robust composites with superior catalytic efficiency. A noted limitation ${ }^{19}$ and crucial disadvantage of this procedure is that silane-containing metalloporphyrins may undergo self-condensation, producing unwanted polymeric species during the silanation process. Therefore, it is necessary to devise a more straightforward and selective method for preparing magnetic nanocomposite-bound metalloporphyrins.

Herein, a facile approach using Huisgen 1,3-dipolar cycloaddition, ${ }^{20}$ commonly known as "click" chemistry, , , is introduced as an alternative method for metalloporphyrin immobilization onto the surface of magnetic silica particles. While eliminating the likelihood of self-condensation, this synthetic strategy gives very high yields, generates only inoffensive byproducts that can be removed by nonchromatographic methods, and is stereoselective. ${ }^{23}$ Also, click chemistry tolerates a variety of functional groups, and is a very rapid reaction. In contrast to random amide formation, click reactions provide site-specific immobilization, as well as higher binding activity. ${ }^{24}$ Overall, this approach is very practical and can be performed under mild reaction conditions in various solvents. In a related report, McDonald et al. ${ }^{25}$ show the click coupling efficiency of alkyne-functionalized metalloporphyrins to azide-functionalized silica substrates. Until now, no previous studies have exploited the advantages of click chemistry to immobilize metalloporphyrins directly onto the surface of spherical, magnetic silica nanoparticles. The present work discusses this preparation, as well as the step-by-step characterization of these superparamagnetic composite-bound catalysts. Some of the findings reported below have appeared in preliminary form.

\section{MATERIALS AND METHODS}

\section{Materials}

Dimethylformamide (DMF), dimethyl sulfoxide (DMSO), hydrogen bromide ( $\mathrm{HBr}, 33 \%$ solution on acetic acid), dichloromethane (DCM), tetraethylorthosilicate (TEOS), $\mathrm{CuBr}$ (99\%), $N, N^{\prime}, N^{\prime}, N^{\prime \prime}$-pentamethyldiethylenetriamine (PMDETA) (99\%), dry tetrahydrofuran (THF). 1,2-Hexadecanediol (97\%), oleic acid (90\%), oleylamine (>70\%), and polyethylenimine (anhydrous, average $M_{\mathrm{w}}$ ca. 25000 ) were purchased from Aldrich. Iron(III) acetylacetonates, $\mathrm{Fe}(\mathrm{acac})_{3}$, was purchased from Strem Chemicals, Inc. (3Bromopropyl)trichlorosilane was purchased from Gelest. All other reagent grade chemicals were used as is without further purification. Analytical thin-layer-chromatography (TLC) was performed on polyester-backed TLC plates 254 (precoated, $200 \mu \mathrm{m}$, Sorbent Technologies) and silica gel 60 (70-230 mesh, Merk) was used for column chromatography. ${ }^{1} \mathrm{H}$ NMR and ${ }^{13} \mathrm{C}$ NMR spectra were obtained using a Bruker AV-4 400 $\mathrm{MHz}$; chemical shifts are expressed in ppm relative to $\left(\mathrm{CD}_{3}\right)_{2} \mathrm{CO}\left(2.05 \mathrm{ppm},{ }^{1} \mathrm{H}\right.$ and 29.84 and $\left.206.26 \mathrm{ppm},{ }^{13} \mathrm{C}\right)$. Mass analyses were conducted at the LSU Mass Spectrometry Facility, on a Bruker Omniflex MALDI-TOF mass spectrometer. 


\section{Methods and Procedures}

Synthesis of $\mathrm{Fe}_{3} \mathrm{O}_{4}$ Nanoparticles-A mixture of $\mathrm{Fe}(\mathrm{acac})_{3}(0.706 \mathrm{~g}, 2 \mathrm{mmol}), 1,2-$ hexadecanediol ( $2.58 \mathrm{~g}, 10 \mathrm{mmol})$, oleic acid $(1.89 \mathrm{~mL}, 6 \mathrm{mmol})$, oleylamine $(1.97 \mathrm{~mL}, 6$ $\mathrm{mmol})$, and phenyl ether $(20 \mathrm{~mL})$ was prepared and magnetically stirred under argon. This solution was heated to $200^{\circ} \mathrm{C}$ for $2 \mathrm{~h}$, followed by reflux $\left(\sim 260^{\circ} \mathrm{C}\right)$ for $1 \mathrm{~h}$. The resulting black mixture was allowed to cool to room temperature. Under ambient conditions, ethanol $(40 \mathrm{~mL})$ was added to the reaction mixture, forming a black precipitate which was separated by centrifugation. The precipitate was dissolved in a mixture of hexane $(30 \mathrm{~mL})$, oleic acid $(0.05 \mathrm{~mL})$, and oleylamine $(0.05 \mathrm{~mL})$. Next, centrifugation $(6000 \mathrm{rpm}$; rotor radius $=13.7$ $\mathrm{cm}, 10 \mathrm{~min}$ ) was used for removal of any nondispersed material. Lastly, the product was precipitated with ethanol, centrifuged (6000 rpm, $10 \mathrm{~min}$ ) to remove the supernatant, and then redispersed in hexane ( $2.9 \mathrm{wt} \%)$. A black-brown hexane dispersion of $\mathrm{Fe}_{3} \mathrm{O}_{4}$ nanoparticles was obtained.

\section{Preparation of Silica-Coated $\mathrm{Fe}_{3} \mathrm{O}_{4}$ Nanoparticles $\left(\mathrm{Fe}_{3} \mathrm{O}_{4} @ \mathrm{SiO}_{2}\right)$-The} $\mathrm{Fe}_{3} \mathrm{O}_{4} @ \mathrm{SiO}_{2}$ nanoparticles were prepared from the synthesized $\mathrm{Fe}_{3} \mathrm{O}_{4}$ nanoparticles. In a $100 \mathrm{~mL}$ three-neck round-bottom flask, a solution of $\mathrm{Fe}_{3} \mathrm{O}_{4}$ nanoparticles $(1 \mathrm{~g}, 3.2 \mathrm{wt} \%)$ was added. To this solution, $\mathrm{H}_{2} \mathrm{O}(8 \mathrm{~mL})$ and ethanol $(32 \mathrm{~mL})$ were also added under nitrogen and vigorous stirring. Aqueous ammonium hydroxide (30 wt \%) and $0.5 \mathrm{~mL}$ of tetraethylorthosilicate (TEOS) were injected and the reaction was continued overnight.

\section{Preparation of Azide-Functionalized Silica-Coated $\mathrm{Fe}_{3} \mathrm{O}_{4}$ Nanoparticles} (Azido- $\mathrm{Fe}_{3} \mathrm{O}_{4} @ \mathrm{SiO}_{2}$ )_A dispersion of $\mathrm{Fe}_{3} \mathrm{O}_{4} @ \mathrm{SiO}_{2}$ nanoparticles $(0.6 \mathrm{~g})$ in toluene (10 $\mathrm{mL}$ ) was bromofunctionalized using (3-bromopropyl)trichlorosilane. The nanoparticles were then isolated with a permanent magnet $(1.25 \mathrm{~T})$ and redispersed in toluene twice. Following a third isolation, the particles were redispersed in DMF, then $\mathrm{NaN}_{3}(0.4 \mathrm{~g})$ and tetrabutylammonium iodide $(0.01 \mathrm{~g})$ were added to the solution. This mixture was heated to $80^{\circ} \mathrm{C}$ and was allowed $24 \mathrm{~h}$ to react while stirring. With a permanent magnet, the azido$\mathrm{Fe}_{3} \mathrm{O}_{4} @ \mathrm{SiO}_{2}$ nanoparticles were isolated and redispersed in DMF, then again in toluene.

Synthesis of Mono-Alkyne Metalloporphyrin (ZnTPP)_A solution of commercially available tetra(4-hydroxyphenyl) porphyrin $\mathbf{1}(340 \mathrm{mg}, 0.5 \mathrm{mmol})$ in DMSO $(60 \mathrm{~mL})$ was mixed with $\mathrm{K}_{2} \mathrm{CO}_{3}(560 \mathrm{mg}, 4 \mathrm{mmol})$, and the reaction mixture was heated at $50{ }^{\circ} \mathrm{C}$ for 15 min under argon. Propargyl bromide $(0.046 \mathrm{~mL}, 0.52 \mathrm{mmol})$ was then added and heating was continued at $50{ }^{\circ} \mathrm{C}$ overnight. The mixture was allowed to cool to room temperature and was then poured into $200 \mathrm{~mL}$ of brine. Crude product was extracted with ethyl acetate and was dried over anhydrous $\mathrm{Na}_{2} \mathrm{SO}_{4}$. The solvent was evaporated under vacuum and the target compound was isolated in a silica gel column, using ethyl acetate/ dichloromethane (30:70) as the eluent. The product was dried under vacuum, with a final yield of $32 \%$ (114 mg, 0.16 mmol). UV-vis (acetone) $\lambda_{\max }\left(\varepsilon / \mathrm{M}^{-1} \mathrm{~cm}^{-1}\right) 420$ (467 600), 515 (46 800), 554 (19 500), 598 (12 100), 653 (9 200). ${ }^{1} \mathrm{H}$ NMR (acetone-d6, $400 \mathrm{MHz}$ ): $\delta 8.93$ (s, 6H, $\beta-\mathrm{H}$ ), 8.83 (s, $2 \mathrm{H}, \beta-\mathrm{H}), 8.02-8.06(\mathrm{~m}, 8 \mathrm{H}), 7.26-7.28(\mathrm{~m}, 8 \mathrm{H}), 4.93\left(\mathrm{~s}, 2 \mathrm{H}, \mathrm{CH}_{2}\right), 3.19(\mathrm{~s}, 1 \mathrm{H}, \mathrm{CH}),-2.64$ (s, $2 \mathrm{H}, \mathrm{NH}) .{ }^{13} \mathrm{C} \mathrm{NMR}\left(\mathrm{CDCl}_{3}, 62.5 \mathrm{MHz}\right): 8157.78,157.49,150.80,150.75,150.53$, 136.92, 135.84, 135.66, 134.93, 131.90, 131.83, 131.60, 121.02, 120.94, 120.11, 114.25, 
113.83, 113.22, 79.50, 76.80, 56.15, 13.97. MALDITOF- MS m/z 717.182 [M + H] for $\mathrm{C}_{47} \mathrm{H}_{32} \mathrm{~N}_{4} \mathrm{O}_{4}$, calculated $717.251[\mathrm{M}+\mathrm{H}]$.

To the above compound (114 $\mathrm{mg}, 0.16 \mathrm{mmol}$ ) dispersed in acetone, saturated $\mathrm{Zn}(\mathrm{OAc})_{2} /$ $\mathrm{MeOH}(5 \mathrm{~mL})$ was added and mixed at room temperature for $24 \mathrm{~h}$. The mixture was poured into water $(100 \mathrm{~mL})$ and extracted with ethyl acetate. The organic layer was evaporated to give a quantitative yield of $98 \%$. UV-vis (acetone) $\lambda_{\max }\left(\varepsilon / \mathrm{M}^{-1} \mathrm{~cm}^{-1}\right) 425$ (467 900), 556 (11 500), 598 (8 100). ${ }^{1} \mathrm{H}$ NMR (acetone-d6, $400 \mathrm{MHz}$ ): $\delta 8.93$ (s, 6H, $\left.\beta-\mathrm{H}\right), 8.88$ (s, 2H, $\beta$ $\mathrm{H}), 8.11(\mathrm{~d}, \mathrm{~J}=8.4,2 \mathrm{H}), 8.03(\mathrm{~d}, \mathrm{~J}=8.12,6 \mathrm{H}) 7.35(\mathrm{~d}, \mathrm{~J}=8.44,2 \mathrm{H}), 7.25(\mathrm{~d}, \mathrm{~J}=8.04,6 \mathrm{H})$, $5.02\left(\mathrm{~s}, 2 \mathrm{H}, \mathrm{CH}_{2}\right), 3.21(\mathrm{~s}, 1 \mathrm{H}, \mathrm{CH})$. MALDI-TOF-MS $778.188[\mathrm{M}]$ for $\mathrm{C}_{47} \mathrm{H}_{30} \mathrm{~N}_{4} \mathrm{O}_{4} \mathrm{Zn}$, calculated $778.168[\mathrm{M}]$.

\section{Synthesis of Magnetic Composite-bound Metalloporphyrins-Azido-}

functionalized $\mathrm{Fe}_{3} \mathrm{O}_{4} @ \mathrm{SiO}_{2}(0.05 \mathrm{~g})$ was dispersed in dry toluene $(10 \mathrm{~mL})$ inside a threeneck round-bottom flask, which was connected to a condenser and nitrogen inlet. The prepared dispersion was degassed for $10 \mathrm{~min}$, and then a degassed solution of alkyneterminated Zn-porphyrin moiety $(0.01 \mathrm{~g})$ in toluene $(10 \mathrm{~mL})$ was added to the mixture. In a different vial, $\mathrm{CuBr}(0.092 \mathrm{~g})$ was weighed and dissolved in toluene $(10 \mathrm{~mL})$, and was capped with a rubber septum. PMDETA $(0.27 \mathrm{~mL})$ was injected into the $\mathrm{CuBr}$ solution with a syringe. After stirring and degassing this solution for $10 \mathrm{~min}$, it was injected into a threeneck reaction vessel which contained the azido-functionalized $\mathrm{Fe}_{3} \mathrm{O}_{4} @ \mathrm{SiO}_{2}$ composites and alkyne-porphyrin moiety. First, this mixture was heated at $60^{\circ} \mathrm{C}$ while stirring for $1 \mathrm{~h}$, and then heated at $40{ }^{\circ} \mathrm{C}$ for $24 \mathrm{~h}$. Once the reaction mixture was cooled to room temperature, the nanocomposite particles were recovered by magnet and centrifugation. To remove any unreacted porphyrins, the particles were redispersed in toluene and recovered three more times. After the final purification, the particles were dispersed in dichloromethane and extracted with distilled $\mathrm{H}_{2} \mathrm{O}$, then repeated with a solution of the sodium salt of EDTA, and again with $\mathrm{H}_{2} \mathrm{O}$ to remove traces of copper. The composite-bound metalloporphyrins were recovered with a magnet, centrifuged and redispersed in methanol three times.

Characterization Methods-All MALDI-TOF spectra were recorded on a Bruker PROFLEX III MALDI-TOF mass spectrometer. Fourier transform infrared (FTIR) spectra were collected using a Bruker Tensor 27 FT-IR spectrometer with a Pike Miracle singlebounce attenuated total reflectance (ATR) cell equipped with a ZnSe single crystal. Thermogravimetric analysis (TGA) was conducted using a TA Instruments TGA Q50 under nitrogen flow with a heating rate of $10^{\circ} \mathrm{C} \mathrm{min}^{-1}$. To monitor the surface composition of the nanoparticles upon chemical modification, a Kratos Analytical Axis $165 \mathrm{X}$-ray photoelectron spectrometer (XPS) with Al Ka X-ray radiation $1486.6 \mathrm{eV}$ and $90^{\circ}$ takeoff angle. Particle size distribution analyses were conducted using a custom-built dynamic light scattering (DLS) apparatus, equipped with a Coherent Innova 90 argon (400-800 nm; used $632.8 \mathrm{~nm}$ ) laser. The device also has a Pacific Precision Instruments (Irvine, California) wide-range photometer/preamplifier/discriminator which drives an ALV pulse shaper and is responsible for feeding an ALV-5000 digital autocorrelator. The nanoparticles were transferred into clean cells with $0.22 \mu \mathrm{m}$ Durapore membrane filters (Millipore Co.). To control the temperature, we used a circulating water bath at a setting of $25 \pm 0.5^{\circ} \mathrm{C}$. Each 
sample was measured three times at several scattering angles with durations of $180 \mathrm{~s}$. The apparent hydrodynamic diameter, $D_{\mathrm{h}}$, was determined by analyses of the averaged correlation functions using one-exponential and third-order cumulant algorithms.

\section{RESULTS AND DISCUSSION}

Monodisperse $\mathrm{Fe}_{3} \mathrm{O}_{4}$ nanoparticles were synthesized using the thermal decomposition method. The reaction of ferric acetylacetonate precursor, Fe-(acac) 3 , with surfactants at high temperature produced stable nanoparticles, which were easily separated from reaction byproducts. Phenyl ether was the chosen solvent because of its high boiling point $\left(259^{\circ} \mathrm{C}\right)$. In a previous comparative study, ${ }^{26}$ the use of phenyl ether as the solvent typically resulted in $4 \mathrm{~nm} \mathrm{Fe}{ }_{3} \mathrm{O}_{4}$ nanoparticles, whereas benzyl ether (b.p., $298^{\circ} \mathrm{C}$ ) led to $6 \mathrm{~nm} \mathrm{Fe}_{3} \mathrm{O}_{4}$. Although this trend indicates that high reaction temperatures contribute to the production of larger particles, monodispersity is only achieved when the reaction mixture is heated to $200{ }^{\circ} \mathrm{C}$ for $2 \mathrm{~h}$ prior to refluxing. Initiating reflux directly from room temperature broadens the particle size distribution (4-15 nm). This phenomenon suggests the $\mathrm{Fe}_{3} \mathrm{O}_{4}$ nucleation and nuclei growth process is slow under these reaction conditions. ${ }^{27}$

The reducing agent, 1,2-hexadecanediol, reacted well with the $\mathrm{Fe}(\mathrm{acac})_{3}$ precursor to produce $\mathrm{Fe}_{3} \mathrm{O}_{4}$ nanocrystals with narrow size distribution and sharp diffraction patterns. However, these physical characteristics, as well as the final yield, tends to diminish when long-chain monoalcohols (e.g., stearyl alcohol) are used as reductants. The combination of oleic acid and oleylamine was also essential for high yields of particles. The presence of these ligands enhances the solubility of complexes in organic solvents (e.g., hexane and chloroform). ${ }^{26}$ In general, oleylamine stabilizes maghemite, $\gamma-\mathrm{Fe}_{2} \mathrm{O}_{3}$, nanocrystals via the coordination of $-\mathrm{NH}_{2}$ with $\mathrm{Fe}^{3+}$ on the particle surface. Using only oleylamine in the reaction provides a low yield of $\mathrm{Fe}_{3} \mathrm{O}_{4}$ nanoparticles. ${ }^{26},{ }^{28}$ In contrast, the exclusive use of oleic acid in the reaction results in a viscous product that is difficult to purify and characterize.

TEM images of monodisperse $\mathrm{Fe}_{3} \mathrm{O}_{4}$ nanoparticles prepared by thermal decomposition are shown in Figure 1. Unlike particles made by coprecipitation methods, agglomeration can be prevented due to the presence of surfactants at the interface. Also, the produced particles have a narrow size-distribution and appear in a self-ordered arrangement. According to DLS data, the average diameter of the $\mathrm{Fe}_{3} \mathrm{O}_{4}$ was $7.8 \pm 1.3 \mathrm{~nm}$. Magnetic materials of this size are considered to be within the superparamagnetic regime $(1-10 \mathrm{~nm}){ }^{29}$

$\mathrm{X}$-ray diffraction (XRD) is useful for acquiring information about the crystallinity of nanoparticles. Figure 2 shows the XRD spectra which confirmed the synthesis of magnetite, exhibiting patterns in agreement with those of standard $\mathrm{Fe}_{3} \mathrm{O}_{4}$ particles. The known standard $\mathrm{Fe}_{3} \mathrm{O}_{4}$ diffraction patterns are indexed to (220), (311), (400), (422), (511), and (440) planes of a cubic unit cell, corresponding to the reflections of the inverse spinel structure of magnetite (JCPDS card no. 19-0629). It so happens that the standard XRD patterns of magnetite and maghemite $\left(\gamma-\mathrm{Fe}_{2} \mathrm{O}_{3}\right.$; JCPDS no. 39-1346) are practically identical. Complementary techniques, such as X-ray photoelectron spectroscopy (XPS), were used to reaffirm the XRD results. 
The superparamagnetism of the $\mathrm{Fe}_{3} \mathrm{O}_{4}$ nanocrystals was measured using a superconducting quantum interference device (SQUID). In Figure 3, the hysteresis loop of the particles at room temperature is shown. Characteristic of superparamagnetic nanocrystals, the $\mathrm{Fe}_{3} \mathrm{O}_{4}$ particles exhibited no hysteresis; the up and down scan signals appeared as a single curve, showing remanence and coercivity were both zero. These properties are pertinent to the magnetic response of the nanoparticles in applications which may require enhanced recyclability and reuse.

The superparamagnetic $\mathrm{Fe}_{3} \mathrm{O}_{4}$ nanoparticles were coated with a layer of silica by microemulsion synthesis, where reverse micelles were exploited as nanoreactors to control the size and monodispersity of the core-shell particles (Scheme 1). These micellar aggregates were composed of surfactants (Igepal CO-520) dispersed in cyclohexane, which was important for compatibilizing oleic acid-stabilized $\mathrm{Fe}_{3} \mathrm{O}_{4}$ and aqueous ammonia. Consequently, a shell of water forms along the interface of the $\mathrm{Fe}_{3} \mathrm{O}_{4}$-Igepal CO-520 composites. ${ }^{30}$ In these water regions of the reverse micelles, silica shells were formed on the surface of the $\mathrm{Fe}_{3} \mathrm{O}_{4}$ nanoparticles by hydrolysis and polymerization of tetraethylorthosilicate (TEOS).

In the microemulsion process, the ratio of Igepal CO-520 to $\mathrm{NH}_{4} \mathrm{OH}$ was used to control the micelle size. This feature was essential for limiting the number of embedded $\mathrm{Fe}_{3} \mathrm{O}_{4}$ particles strictly to one per micelle because what holds for the micelle does not necessarily hold for the particle. The probability of encapsulating multiple magnetic cores in a single composite increased as a function of silica shell thickness. In regards to the magnetization of $\mathrm{Fe}_{3} \mathrm{O}_{4}$ nanocrystals, their intrinsic properties are independent of shell thickness, and it is not expected that their magnetic response will be reduced after coating them with silica. However, magnetization is measured in units of emu/gram, so the total weight of silicacoated $\mathrm{Fe}_{3} \mathrm{O}_{4}$ particles versus the weight of bare $\mathrm{Fe}_{3} \mathrm{O}_{4}$ will yield measurements that appear counterintuitive. Increasing the total mass of the particles after silica-coating without increasing their magnetic moments will suggest a reduction in magnetization. No correction for this effect was attempted. To demonstrate the magnetic response of the prepared $\mathrm{Fe}_{3} \mathrm{O}_{4} @ \mathrm{SiO}_{2}$ nanoparticles in the presence of an external field, we held a strong permanent magnet next to the dispersion (Figure 4). The observed particle behavior confirmed the magnetic properties of $\mathrm{Fe}_{3} \mathrm{O}_{4}$ after being coated with a layer of silica.

TEM images of the synthesized $\mathrm{Fe}_{3} \mathrm{O}_{4} @ \mathrm{SiO}_{2}$ nanoparticles are shown in Figure 5. According to the measured particle size, the prepared composites had a narrow size distribution (20-25 nm). The average composite diameter was $23 \pm 1.8 \mathrm{~nm}$ and the silica shell thickness was $\sim 6 \mathrm{~nm}$. Although the silica shell was clearly visible in the TEM images, it was also confirmed by the presence of a broad peak in XRD. The measured diffraction peaks of the $\mathrm{Fe}_{3} \mathrm{O}_{4} @ \mathrm{SiO}_{2}$ nanocomposites agreed with those of standard $\mathrm{Fe}_{3} \mathrm{O}_{4}$. However, unlike the XRD pattern of bare $\mathrm{Fe}_{3} \mathrm{O}_{4}$, the spectrum of $\mathrm{Fe}_{3} \mathrm{O}_{4} @ \mathrm{SiO}_{2}$ has a distinct broad peak that indicates the presence of the silica shell (Figure 2).

\section{Superparamagnetic Azido-Functionalized $\mathrm{Fe}_{3} \mathrm{O}_{4} @ \mathrm{SiO}_{2}$ Nanoparticles}

In the preparation of azido-functionalized silica-coated superparamagnetic iron oxide nanoparticles (SPIONs), a series of surface modifications was performed (Scheme 2). Prior 
to functionalizing the $\mathrm{Fe}_{3} \mathrm{O}_{4} @ \mathrm{SiO}_{2}$ particles with azide groups, the particles were bromofunctionalized via condensation of (3-bromopropyl)trichlorosilane onto the nanocomposites. Bromo-functionalization of the particle surface was confirmed using XPS (Figure 6). In combination with peaks corresponding to silica-coated $\mathrm{Fe}_{3} \mathrm{O}_{4}$ (i.e., $\mathrm{Si} 2 \mathrm{~s}, \mathrm{Si} 2 \mathrm{p}, \mathrm{C}$ 1s, O1s, and $\mathrm{Fe} 2 \mathrm{p}$ ), the presence of bromine groups was indicated by a $\mathrm{Br} 3 \mathrm{p}$ peak at $188 \mathrm{eV}$ and a less intense $\mathrm{Br} 3 \mathrm{~d}$ peak at $70 \mathrm{eV}$. $^{24}$

The bromo-functionalized nanoparticles were azido-functionalized via nucleophilic substitution of the bromine groups using $\mathrm{NaN}_{3}$ in DMF. In this reaction, tetrabutylammonium iodide was used as a catalyst. Following the reaction, XPS was used to confirm the presence of azide groups on the particle surface. The disappearance of the $\mathrm{Br} 3 \mathrm{~d}$ peak and emergence of an $\mathrm{N} 1$ s peak at $\sim 400 \mathrm{eV}$ suggest the bromine/azide substitution occurred (Figure 6A inset). However, the Br 3p peak was still slightly visible, which was evidence that perhaps traces of bromine remained.

In an effort to resolve the XPS results, additional information was obtained from the FTIR spectra of azide-functionalized $\mathrm{Fe}_{3} \mathrm{O}_{4} @ \mathrm{SiO}_{2}$ versus unmodified $\mathrm{Fe}_{3} \mathrm{O}_{4} @ \mathrm{SiO}_{2}$ nanoparticles (see Figure 7). The characteristic absorption peaks at 441, 585, and $632 \mathrm{~cm}^{-1}$ are attributed to the $\mathrm{Fe}-\mathrm{O}$ structure. For the silica shell, absorption peaks corresponding to $\mathrm{Si}-\mathrm{O}-\mathrm{Si}$ stretching, $\mathrm{Si}-\mathrm{OH}$ stretching, $\mathrm{Si}-\mathrm{O}$ bending, and $\mathrm{Si}-\mathrm{O}-\mathrm{Si}$ bending, are displayed at 1095 , 945,802 , and $461 \mathrm{~cm}^{-1}$, respectively. ${ }^{31}$ The spectrum of the azide-functionalized $\mathrm{Fe}_{3} \mathrm{O}_{4} @ \mathrm{SiO}_{2}$ composites showed a distinct absorption peak at $2100 \mathrm{~cm}^{-1}$ corresponding to the presence of azide groups. Further evidence of azide functionalization was revealed by the disappearance of the $\mathrm{Si}-\mathrm{OH}$ peak at $945 \mathrm{~cm}^{-1}$.

\section{Alkyne-Functionalized Porphyrin}

The synthesized alkyne-functionalized metalloporphyrins were specifically designed for "click chemistry" conjugation to azide-groups (Scheme 3). The reaction involved the monoalkylation of commercially available tetra(4-hydroxyphenyl) porphyrin $\mathbf{1}$ using $\mathrm{K}_{2} \mathrm{CO}_{3}$ as the base in DMSO, followed by $o$-alkylation with propargyl bromide. To limit the formation of di-, tri-, and tetra-alkylated products, it was important to optimize the stoichiometry of the reagents. This was done by using a 1:1 ratio for the reaction of a single propargyl bromide group with each porphyrin molecule. The exact ratio of tetra(4hydroxyphenyl) porphyrin $1, \mathrm{~K}_{2} \mathrm{CO}_{3}$, and propargyl bromide was 1:8:1.04, respectively.

\section{Silica-Coated Iron Oxide Bound Porphyrin Nano-composites}

Attachment of the Zn-porphyrin derivatives to superparamagnetic composites was performed by reacting azido-functionalized $\mathrm{Fe}_{3} \mathrm{O}_{4} @ \mathrm{SiO}_{2}$ with alkyne-conjugated metalloporphyrins using copper-catalyzed Huisgen 1,3-dipolar cycloaddition (“click”). CuBr/PMDETA constituted the catalyst system, where PMDETA served as a ligand to increase the rate of copper-catalyzed azide-alkyne cycloaddition in organic media. ${ }^{24}$ Once the reaction was complete, the ZnTPP-conjugated nanoparticles were collected using a magnet and was redispersed in methanol. This process was repeated several times to remove free unreacted porphyrins from the solution. All traces of copper were removed via extraction using an aqueous solution of the sodium salt of EDTA. 
In the case of free-base porphyrin species as the final targeted form, it is still important to metalate the porphyrins prior to performing the click reaction. As seen in past studies, ${ }^{32}$ the copper-catalyzed Huisgen 1,3-dipolar cycloaddition is extremely difficult with free-base porphyrin derivatives, due to the insertion of copper inside the macrocycle core. This phenomenon inherently occurs because free-base porphyrins are capable of binding to metal ions to form metalloporphyrin complexes (e.g., heme and chlorophyll). By first metallating the porphyrin, copper insertion then becomes inhibited, thus preventing catalyst deactivation. Once the reaction is complete, the final click-conjugated free-base product can be obtained via demetalation using TFA (see Scheme 4). This strategy has been shown to greatly enhance the reactivity of porphyrin click chemistry, producing high yields.

To characterize the $\mathrm{Fe}_{3} \mathrm{O}_{4} @ \mathrm{SiO}_{2}$-click-ZnTPP nanoparticles, a series of techniques was used, which included TEM, TGA, FTIR, and XPS. High-resolution TEM images of the composites are shown in Figure 8. Similar to the images of bare silica-coated $\mathrm{Fe}_{3} \mathrm{O}_{4}$, the core and shell can clearly be identified by electron diffraction; the core is crystalline, whereas the shell is amorphous (Supporting Information). The $\mathrm{Fe}_{3} \mathrm{O}_{4} @ \mathrm{SiO}_{2}$-click-ZnTPP nanocomposites appear to have a better defined shell, which may be due to the ZnTPP attached to the surface. Also, according to the DLS results, the diameter of the click-reacted particles is $32 \pm 3 \mathrm{~nm}$.

Figure 9 shows the TGA traces of each synthesized component of the nanocomposite before and after coating and conjugation; the TGA curve of alkyne-metalloporphyrin is shown in the inset. Two degradation stages were observed for the $\mathrm{Fe}_{3} \mathrm{O}_{4}$ nanoparticles, where the initial mass loss observed at $210{ }^{\circ} \mathrm{C}$ is perhaps due to the removal of surface absorbed components, including ethanol and free or weakly bound oleic acid. ${ }^{33}$ The second mass loss between 310 and $550{ }^{\circ} \mathrm{C}$ corresponds to the loss of covalently bound oleic acid molecules. ${ }^{34}$ In TGA traces of the silica-coated $\mathrm{Fe}_{3} \mathrm{O}_{4}$ particles, two distinct degradation stages were also observed. Within the temperature range of 30 and $130{ }^{\circ} \mathrm{C}$, the weight loss was attributed to the removal of physisorbed and chemisorbed water, as well as any other residual solvent. Further mass loss seen between 130 and $600{ }^{\circ} \mathrm{C}$ was attributed to dehydroxylation of surface silanols, yielding siloxane groups and the removal of any unhydrolyzed ethoxy groups originating from TEOS. Also, some of the mass loss that occurred between 200 and $400{ }^{\circ} \mathrm{C}$ may have resulted from the burning off of residual surfactant. ${ }^{35}$ The TGA curve for the silica- $\mathrm{Fe}_{3} \mathrm{O}_{4}$-click-metalloporphyrins exhibited weight loss between room temperature and $200{ }^{\circ} \mathrm{C}$, due to water and unreacted azide groups. ${ }^{24},{ }^{36}$ This particular nanocomposite also displayed the highest thermal stability and resistance to decomposition, which may be due to the addition of inorganic materials on the particle surface.

The $\mathrm{Fe}_{3} \mathrm{O}_{4} @ \mathrm{SiO}_{2}$-click-ZnTPP nanoparticles were further analyzed using XPS (Figure 10). As shown in Figure 10b, the combination of elemental peaks from both ZnTPP and $\mathrm{Fe}_{3} \mathrm{O}_{4} @ \mathrm{SiO}_{2}$ is clearly visible in the survey scan of the click-reacted composites. Highresolution scans of the N 1s region of free ZnTPP (Figure 10b) and the final ZnTPP-bound magnetic particles (Figure 10e) showed two peaks. A single peak at $398.2 \mathrm{eV}$ is expected, indicating all four nitrogen atoms in the porphyrin ring are coordinated to the zinc atom. However, the two nitrogen atom peaks at binding energies of 399.6 and $397.8 \mathrm{eV}$ correspond to protonated and deprotonated nitrogens, respectively; this is a characteristic feature of 
metal-free porphyrins. ${ }^{37}, 38$ In Figure 11, the Zn $2 p$ spectra show the spin-orbit pair of the $2 p_{3 / 2}$ component at $1021.5 \mathrm{eV}$, which indicates a reduction from the $\mathrm{Zn}^{2+}$ oxidative state $(1022.4 \mathrm{eV})$ to the neutral $\mathrm{Zn}^{0}$ state. These complementary results confirmed the loss of zinc by the porphyrin macrocycle, perhaps due to grinding the sample during preparation. ${ }^{39}$

In Figure 12, the FTIR spectra of alkyne-ZnTPP and $\mathrm{Fe}_{3} \mathrm{O}_{4} @ \mathrm{SiO}_{2}$-click-ZnTPP are shown. The characteristic absorption bands of ZnTPP were observed for the pure alkyne-ZnTPP compound, exhibiting peaks at 1356,792, and $996 \mathrm{~cm}^{-1}$, which correspond to vibration of $\mathrm{C}=\mathrm{N}$ in the porphyrin macrocycle, the skeletal vibration of the porphyrin ring, and vibration of $\mathrm{N}-\mathrm{Zn}$, respectively. Due to band overlap from the $\mathrm{Fe}_{3} \mathrm{O}_{4} @ \mathrm{SiO}_{2}$ component, it is difficult to discern some of these features in the IR spectra of the porhyrin-bound hybrid particles. Relative to the IR spectra of azide-functionalized $\mathrm{Fe}_{3} \mathrm{O}_{4} @ \mathrm{SiO}_{2}$ (Figure 7), though, the absorption band of $\mathrm{Fe}_{3} \mathrm{O}_{4} @ \mathrm{SiO}_{2}$-click-ZnTPP at $2100 \mathrm{~cm}^{-1}$ diminishes, indicating the reaction of azide groups. Moreover, a new absorption band appears at $1597 \mathrm{~cm}^{-1}$, which is a spectroscopic feature of the triazole unsaturations. ${ }^{40}$ These combined results confirmed the covalent attachment of $\mathrm{ZnTPP}$ onto the surface of $\mathrm{Fe}_{3} \mathrm{O}_{4} @ \mathrm{SiO}_{2}$.

\section{CONCLUSIONS}

Metalloporphyrin-bound superparamagnetic, silica-coated $\mathrm{Fe}_{3} \mathrm{O}_{4}$ nanoparticles were successfully prepared using click chemistry. The thermal decomposition method produced monodisperse, oleic-acid stabilized $\mathrm{Fe}_{3} \mathrm{O}_{4}$ nanoparticles, which exhibit superparamagnetic properties. This method can also be extended to the synthesis of other $\mathrm{MFe}_{2} \mathrm{O}_{4}$ nanoparticles (i.e., $\mathrm{M}=\mathrm{Co}, \mathrm{Ni}, \mathrm{Mn}, \mathrm{Mg}$, etc.) by simply adding a different metal acetylacetonate precursor to the reaction mixture. The magnetic $\mathrm{Fe}_{3} \mathrm{O}_{4}$ nanoparticles were coated with silica in a controlled fashion with the microemulsion synthesis, which produces monodisperse coreshell nanoparticles. After azido-functionalization of the modified silica surface, the particles were readily available for click chemistry via the reaction with zinc-complexed metalloporphyrins which possessed an alkyne moiety. Such a versatile approach can be extended to other photoreactive systems, such as phthalocyanines and borondipyrromethene, which may lead to new materials for optical, photonic, and biological applications.

\section{Supplementary Material}

Refer to Web version on PubMed Central for supplementary material.

\section{Acknowledgments}

This material is based on work partially supported by NSF 1005707 Division of Materials Research, Polymers Program. J.H. was also supported by NSF OISE-115189. We thank Dr. Song Hong for the TEM images and Dr. Giri Jyotsnendu for his assistance with characterizing the magnetic particles.

\section{REFERENCES}

1. Hollingsworth, JV. Ph.D. Dissertation. Baton Rouge, LA: Louisiana State University; 2012. Synthesis, Characterization, and Self-Assembly of Porphyrins Conjugated to Superparamagnetic Colloidal Particles for Enhanced Photodynamic Therapy. http://etd.lsu.edu/docs/available/ etd-11162012-103236/ 
2. Kessel D. Photodynamic Therapy: From the Beginning. Photodiagn. Photodyn. Ther. 2004; 1:3-7.

3. Munro AW, Girvan HM, Mason AE, Dunford AJ, McLean KJ. What Makes a P450 Tick? Trends Biochem. Sci. 2013; 38:140-150. [PubMed: 23356956]

4. Saeedi MS, Tangestaninejad S, Moghadam M, Mirkhani V, Mohammadpoor-Baltork I, Khosropour AR. Manganese Porphyrin Immobilized on Magnetite Nanoparticles as a Recoverable Nanocatalyst for Epoxidation of Olefins. Mater. Chem. Phys. 2014; 146:113-120.

5. Bahramian B, Mirkhani V, Moghadam M, Tangestaninejad S. Manganese (III) Salen Immobilized on Montmorillonite as Biomimetic Alkene Epoxidation and Alkane Hydroxylation Catalyst with Sodium Periodate. Catal. Commun. 2006; 7:289-296.

6. Cai JH, Huang JW, Yu HC, Ji LN. Manganeseporphyrins Immobilized on Silica Microspheres as Biomimetic Catalysts Hydroxylating Cyclohexane with Molecular Oxygen. J. Sol-Gel Sci. Technol. 2011; 58:698-704.

7. Dan-Hua S, Lin-Tao J, Zhi-Gang L, Wen-bin S, Can-cheng G. Ethylbenzene Oxidation Over Hybrid Metalloporphyrin@Silica Nano-composite Microspheres. J. Mol. Catal. A: Chem. 2013; 379:15-20.

8. Yin Y, Dong Z, Luo Q, Liu J. Biomimetic Catalysts Designed on Macromolecular Scaffolds. Prog. Polym. Sci. 2012; 37:1476-1509.

9. Boruah JJ, Das SP, Borah R, Gogoi SR, Islam NS. Polymer-Anchored Peroxo Compounds of Molybdenum and Tungsten as Efficient and Versatile Catalysts for Mild Oxidative Bromination. Polyhedron. 2013; 52:246-254.

10. Araghi M, Bokaei F. Manganese(III) Porphyrin Supported on Multi-Wall Carbon Nanotubes: A Highly Efficient and Reusable Biomimetic Catalyst for Oxidative Decarboxylation of aArylcarboxylic Acids and Oxidation of Alkanes with Sodium Periodate. Polyhedron. 2013; 53:1519.

11. Johansson M, Purse BW, Terasaki O, Bäckvall J-E. Aerobic Oxidations Catalyzed by ZeoliteEncapsulated Cobalt Salophen. Adv. Synth. Catal. 2008; 350:1807-1815.

12. Maurya MR, Chandrakar AK, Chand S, Zeolite Y. Encapsulated Metal Complexes of Oxovanadium (VI), Copper (II) and Nickel (II) as Catalyst for the Oxidation of Styrene, Cyclohexane and Methyl Phenyl Sulfide. J. Mol. Catal. A: Chem. 2007; 274:192-201.

13. Kannan V, Sreekumar K. Clay Supported Titanium Catalyst for the Solvent Free Synthesis of Tetrasubstituted Imidazoles and Benzimidazoles. J. Mol. Catal. A: Chem. 2013; 376:34-39.

14. Zhang Y, Zhaorigetu B, Jia M, Chen C, Zhao J. Clay-Based $\mathrm{SiO}_{2}$ as Active Support of Gold Nanoparticles for CO Oxidation Catalyst: Pivotal Role of Residual Al. Catal. Commun. 2013; 35:72-75.

15. Tudorache M, Protesescu L, Negoi A, Parvulescu VI. Recyclable Biocatalytic Composites of Lipase-Linked Magnetic Macro-/Nano-Particles for Glycerol Carbonate Synthesis. Appl. Catal., A. 2012; 437-438:90-95.

16. Eriksson K, Göthelid E, Puglia C, Bäckvall J-E, Oscarsson S. Performance of a Biomimetic Oxidation Catalyst Immobilized on Silica Particles. J. Catal. 2013; 303:16-21.

17. Sadeghi O, Amini M, Bazargani M, Mehrani A, Aghabali A, Adineh M, Amani V, Mehrani K. Immobilization of Metalloporphyrin on Functionalized Magnetic Nanoparticles as a Catalyst in Oxidation of Cyclohexene: Novel Modified $\mathrm{Fe}_{3} \mathrm{O}_{4}$ Nanoparticles with Triethoxysilane Agent. J. Inorg. Organomet. Polym. Mater. 2012; 22:530-535.

18. Ucoski GM, Nunes FS, DeFreitas-Silva G, Idemori YM, Nakagaki S. Metalloporphyrins Immobilized on Silica-Coated $\mathrm{Fe}_{3} \mathrm{O}_{4}$ Nanoparticles: Magnetically Recoverable Catalysts for the Oxidation of Organic Substrates. Appl. Catal., A. 2013; 459:121-130.

19. Liu C-X, Liu Q, Guo C-C, Tan Z. Preparation and Characterization of Novel Magnetic Nanocomposite-Bonded Metalloporphyrins as Biomimetic Nanocatalysts. J. Porphyrins Phthalocyanines. 2010; 14:825-831.

20. Huisgen R. 1,3-Dipolar Cycloadditions. Past and Future. Angew. Chem., Int. Ed. Engl. 1963; 2:565-598.

21. Kolb HC, Finn MG, Sharpless KB. Click Chemistry: Diverse Chemical Function from a Few Good Reactions. Angew. Chem., Int. Ed. 2001; 40:2004-2021.

22. Uppal T, Bhupathiraju NVSDK, Vicente MGH. Synthesis and Cellular Properties of Near-IR BODIPY-PEG and Carbohydrate Conjugates. Tetrahedron. 2013; 69:4687-4693. 
23. Lutz J-F. 1,3-Dipolar Cycloadditions of Azides and Alkynes: A Universal Ligation Tool in Polymer and Materials Science. Angew. Chem., Int. Ed. 2007; 46:1018-1025.

24. Balamurugan SS, Soto-Cantu E, Cueto R, Russo PS. Preparation of Organosoluble SilicaPolypeptide Particles by "Click" Chemistry. Macromolecules. 2010; 43:62-70.

25. McDonald AR, Franssen N, van Klink GPM, van Koten G. 'Click' Silica Immobilisation of Metallo-Porphyrin Complexes and Their Application in Epoxidation Catalysis. J. Organomet. Chem. 2009; 694:2153-2162.

26. Sun S, Zeng H, Robinson DB, Raoux S, Rice PM, Wang SX, Li G. Monodisperse $\mathrm{MFe}_{2} \mathrm{O}_{4}(\mathrm{M}=$ Fe, Co, Mn) Nanoparticles. J. Am. Chem. Soc. 2004; 126:273-279. [PubMed: 14709092]

27. Watzky MA, Finke RG. Transition Metal Nanocluster Formation Kinetic and Mechanistic Studies. A New Mechanism When Hydrogen Is the Reductant: Slow, Continuous Nucleation and Fast Autocatalytic Surface Growth. J. Am. Chem. Soc. 1997; 119:10382-10400.

28. Rajamathi M, Ghosh M, Seshadri R. Hydrolysis and Amine-Capping in a Glycol Solvent as a Route to Soluble Maghemite Gamma- $\mathrm{Fe}_{2} \mathrm{O}_{3}$ Nanoparticles. Chem. Commun. (Cambridge, U.K.). 2002:1152-1153.

29. Teja AS, Koh P-Y. Synthesis, Properties, and Applications of Magnetic Iron Oxide Nanoparticles. Prog. Cryst. Growth Charact. Mater. 2009; 55:22-45.

30. Zhang M, Cushing BL, O'Connor CJ. Synthesis and Characterization of Monodisperse Ultra-Thin Silica-Coated Magnetic Nanoparticles. Nanotechnology. 2008; 19:085601. [PubMed: 21730725]

31. Lien Y-H, Wu T-M. Preparation and Characterization of Thermosensitive Polymers Grafted onto Silica-Coated Iron Oxide Nanoparticles. J. Colloid Interface Sci. 2008; 326:517-521. [PubMed: 18667211]

32. Nikolaou V, Angaridis PA, Charalambidis G, Sharma GD, Coutsolelos AG. A "Click-Chemistry" Approach for the Synthesis of Porphyrin Dyads as Sensitizers for Dye-Sensitized Solar Cells. Dalton Trans. 2015; 44:1734-1747. [PubMed: 25465056]

33. Kwon SG, Piao Y, Park J, Angappane S, Jo Y, Hwang N-M, Park J-G, Hyeon T. Kinetics of Monodisperse Iron Oxide Nanocrystal Formation by "Heating-Up" Process. J. Am. Chem. Soc. 2007; 129:12571-12584. [PubMed: 17887758]

34. Ozel F, Kockar H, Beyaz S, Karaagac O, Tanrisever T. Superparamagnetic Iron Oxide Nanoparticles: Effect of Iron Oleate Precursors Obtained with a Simple Way. J. Mater. Sci.: Mater. Electron. 2013; 24:3073-3080.

35. Chandradass J, Kim KH. Synthesis and Characterization of $\mathrm{CuAl}_{2} \mathrm{O}_{4}$ Nanoparticles via a Reverse Microemulsion Method. J. Ceram. Process. Res. 2010; 11:150-153.

36. Blomberg S, Ostberg S, Harth E, Bosman AW, Van Horn B, Hawker CJ. Production of Crosslinked, Hollow Nanoparticles by Surface-Initiated Living Free-Radical Polymerization. J. Polym. Sci., Part A: Polym. Chem. 2002; 40:1309-1320.

37. Zeller MV, Hayes RG. X-Ray Photoelectron Spectroscopic Studies on the Electronic Structures of Porphyrin and Phthalocyanine Compounds. J. Am. Chem. Soc. 1973; 95:3855-3860. [PubMed: 4710056]

38. Rienzo A, Mayor LC, Magnano G, Satterley CJ, Ataman E, Schnadt J, Schulte K, O'Shea JN. XRay Absorption and Photoemission Spectroscopy of Zinc Protoporphyrin Adsorbed on Rutile $\mathrm{TiO}_{2}$ (110) Prepared by In Situ Electrospray Deposition. J. Chem. Phys. 2010; 132:084703. [PubMed: 20192313]

39. Guilard R, Kadish KM. Some Aspects of Organometallic Chemistry in Metalloporphyrin Chemistry: Synthesis, Chemical Reactivity, and Electrochemical Behavior of Porphyrins with Metal-Carbon Bonds. Chem. Rev. 1988; 88:1121-1146.

40. Xue Y, Ma D, Zhang T, Lin S, Shao S, Gu N. Synthesis and Characterization of Comb-Like Methoxy Polyethylene Glycol-Grafted Polyurethanes via ‘Click' Chemistry. J. Macromol. Sci., Part A: Pure Appl. Chem. 2014; 51:456-464. 

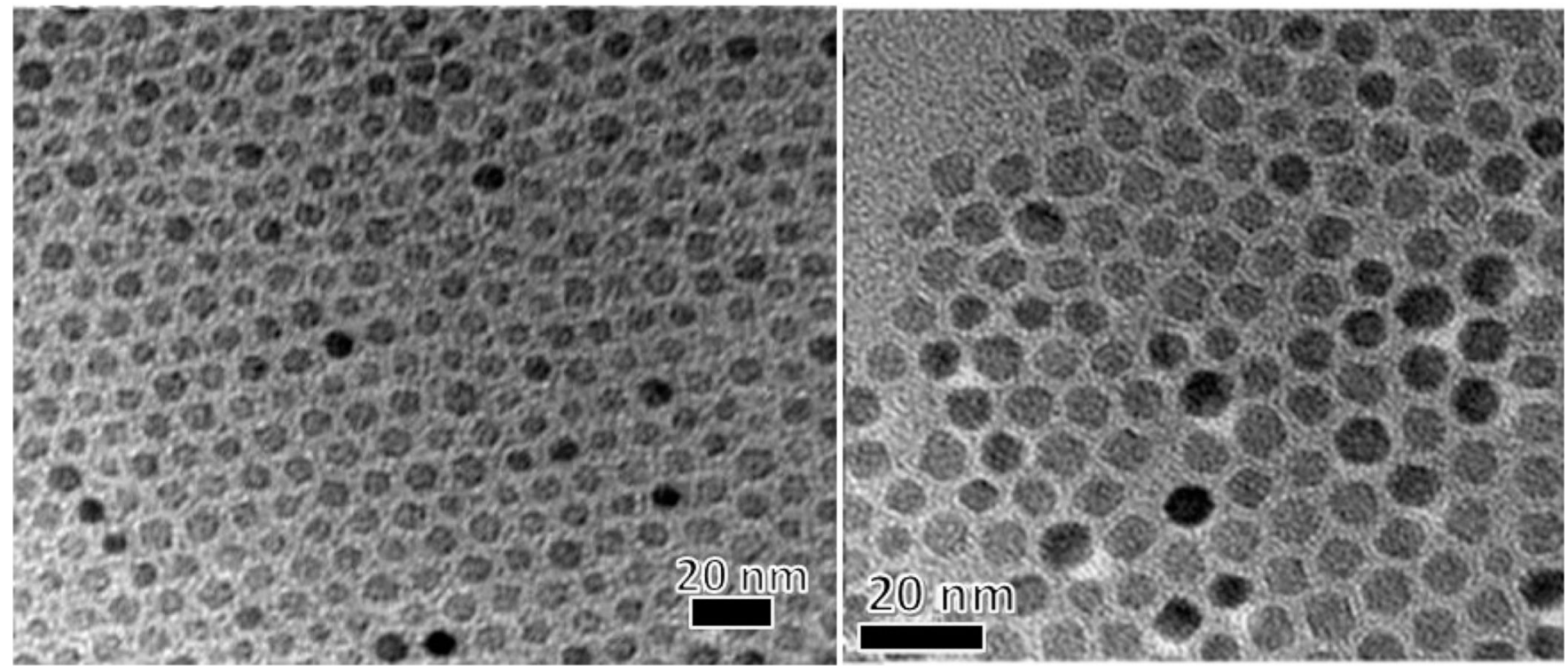

Figure 1.

TEM images of a monolayer of $\mathrm{Fe}_{3} \mathrm{O}_{4}$ nanoparticles prepared via thermal decomposition. 


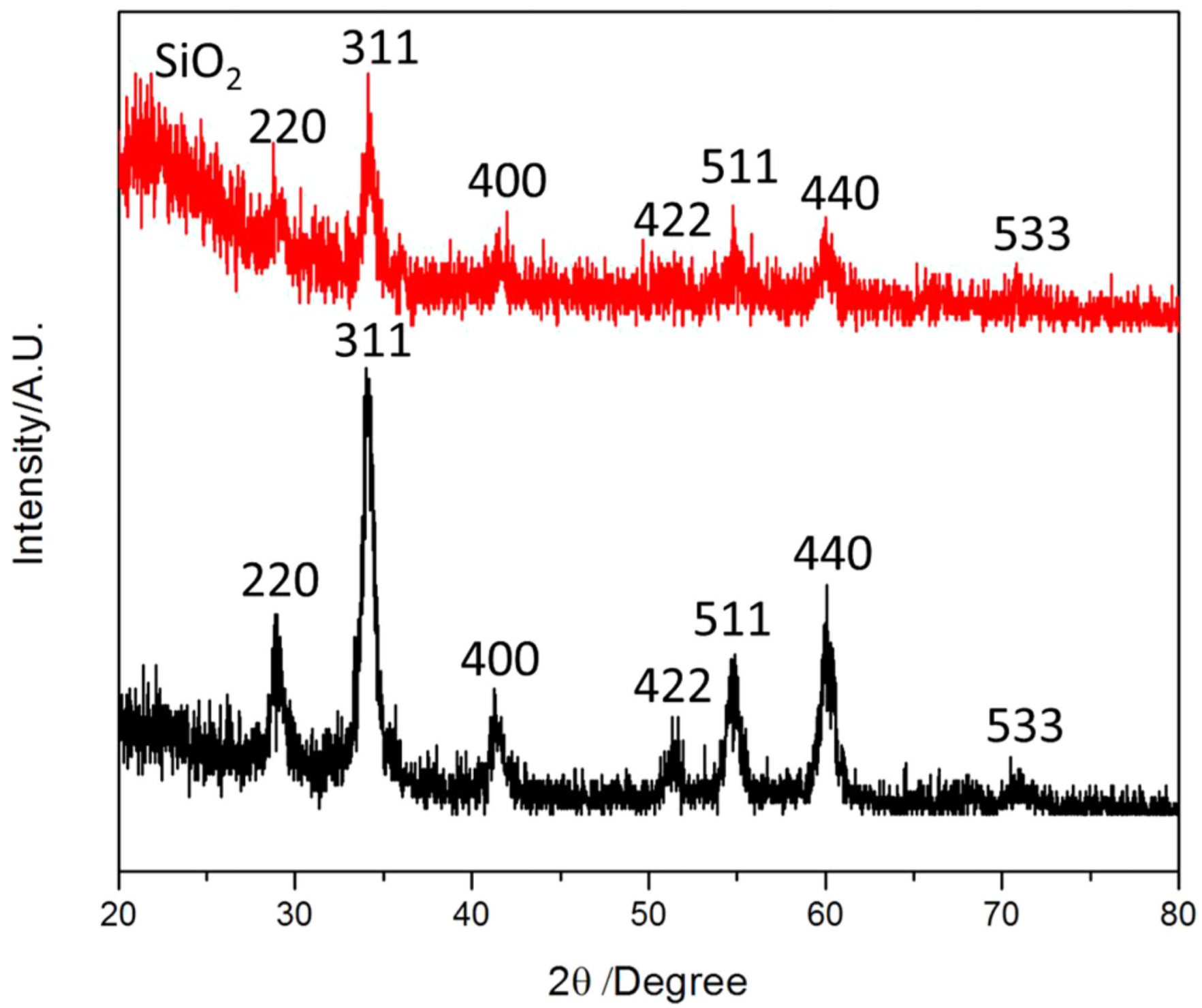

Figure 2.

XRD pattern of (black) $\mathrm{Fe}_{3} \mathrm{O}_{4}$ and (red) silica-coated $\mathrm{Fe}_{3} \mathrm{O}_{4}$ nanoparticles. 


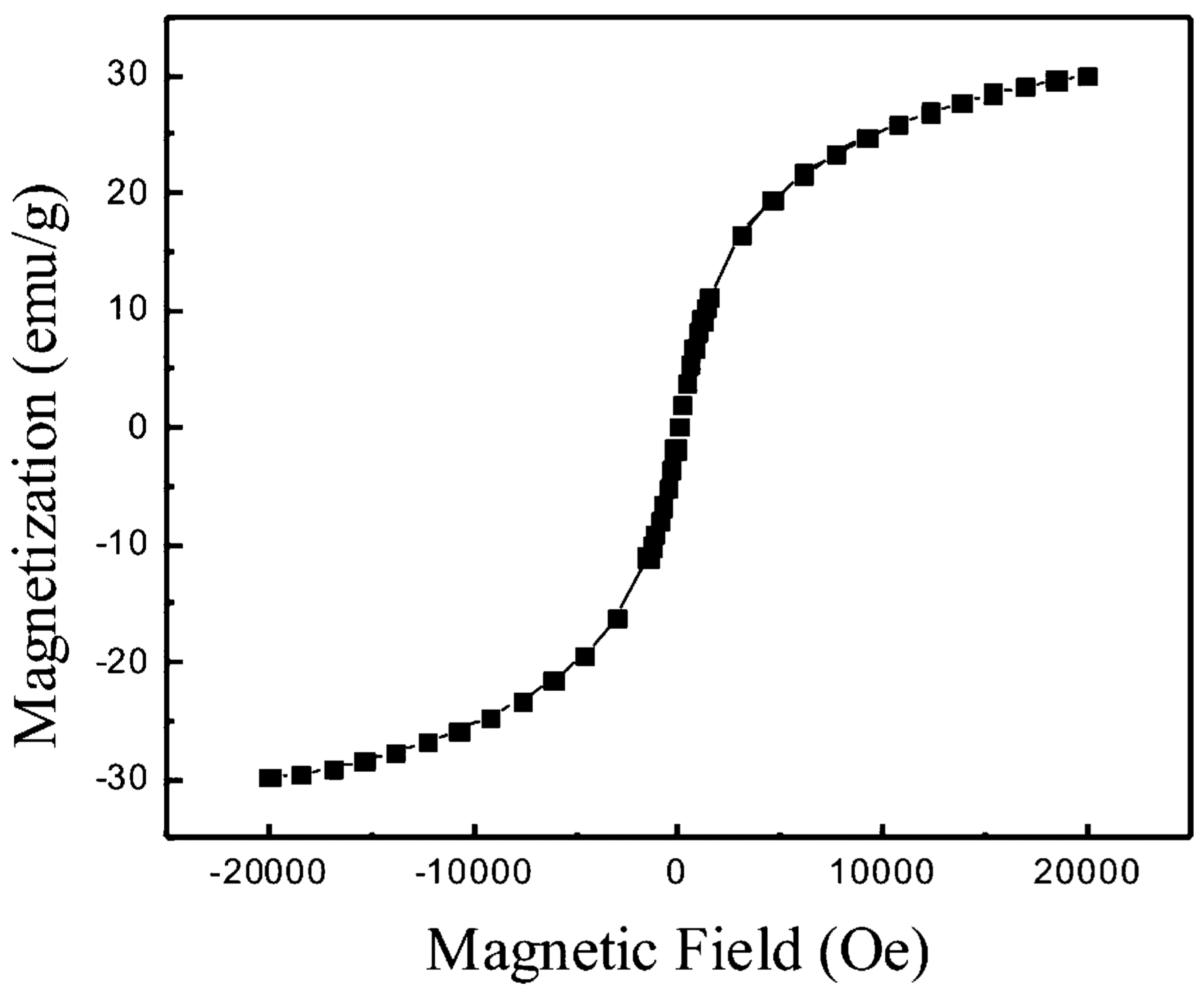

Figure 3.

Hysteresis loop of $\mathrm{Fe}_{3} \mathrm{O}_{4}$ nanoparticles at room temperature. The magnetization (M) vs applied field $(\mathrm{H})$ of $\mathrm{Fe}_{3} \mathrm{O}_{4}$ shows no coercivity or magnetic remanence. 

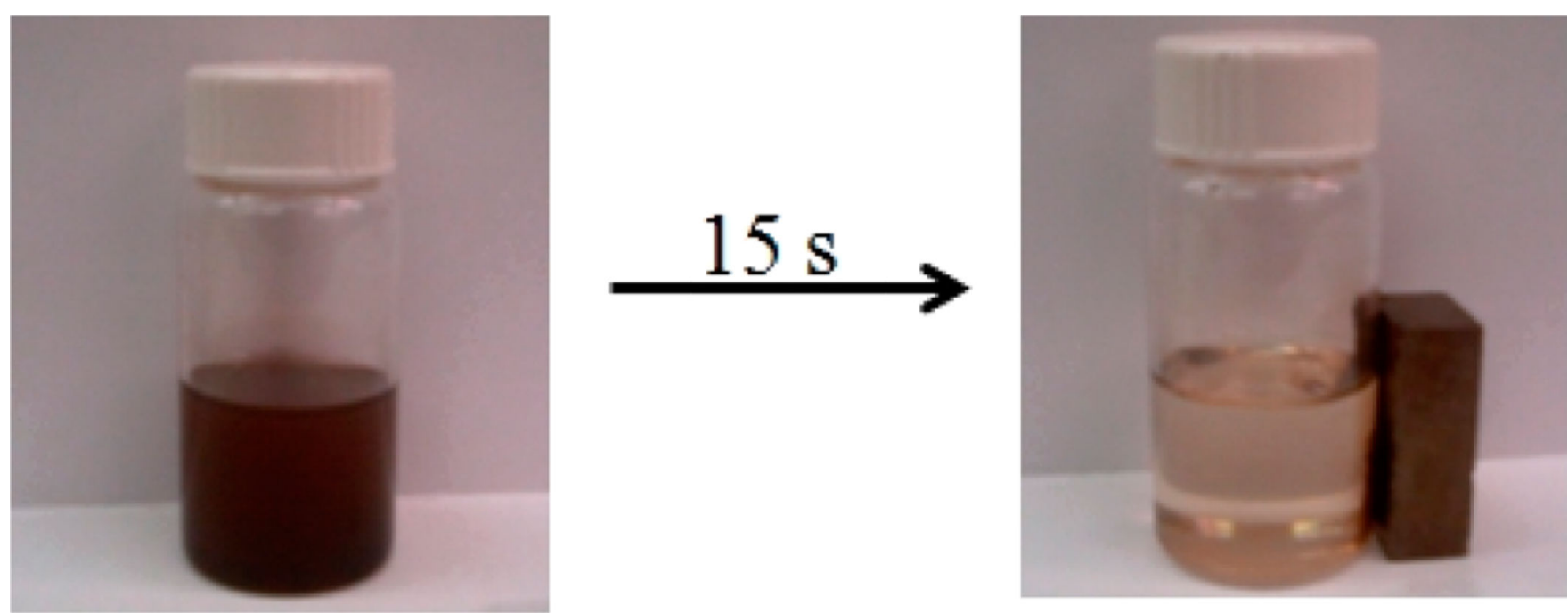

Figure 4.

Demonstration of the magnetic response of the prepared $\mathrm{Fe}_{3} \mathrm{O}_{4} @ \mathrm{SiO}_{2}$ nanocomposites in the absence (left) and presence (right) of a strong permanent magnet. 


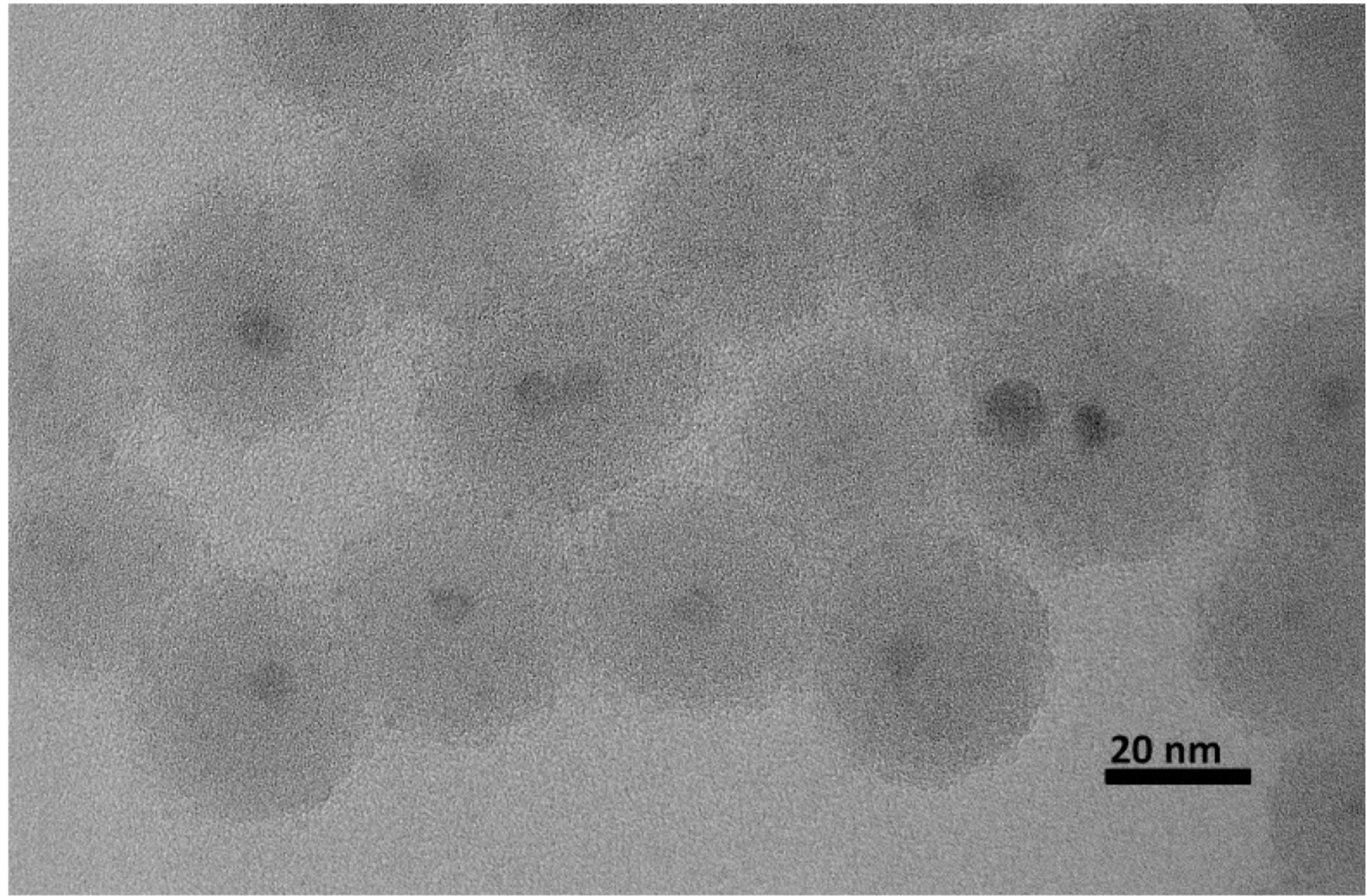

Figure 5.

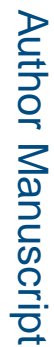

TEM images of $\mathrm{Fe}_{3} \mathrm{O}_{4} @ \mathrm{SiO}_{2}$ nanoparticles prepared using the microemulsion method. 


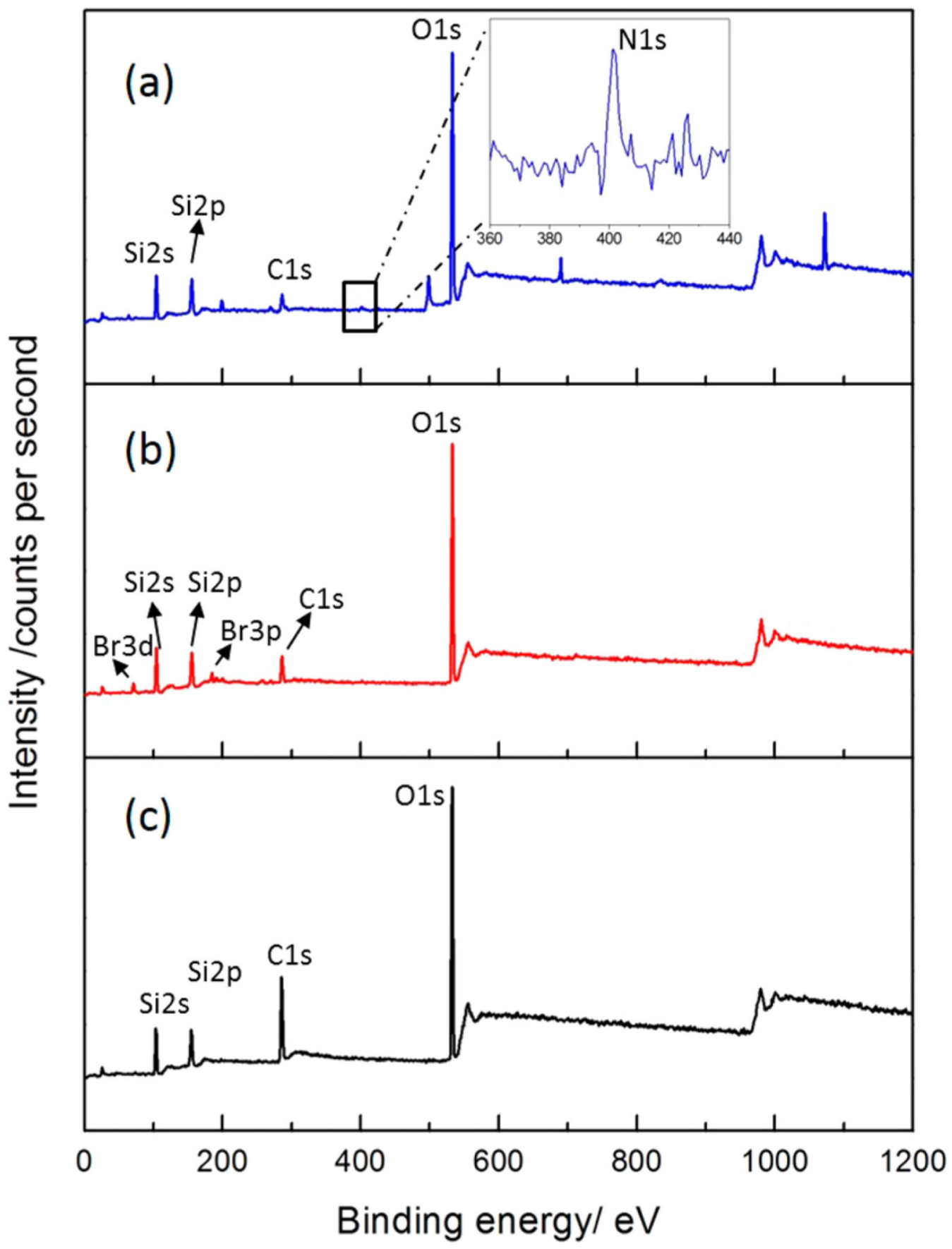

Figure 6.

XPS survey scans of (a) azide-functionalized $\mathrm{Fe}_{3} \mathrm{O}_{4} @ \mathrm{SiO}_{2}$, (b) bromo-functionalized $\mathrm{Fe}_{3} \mathrm{O}_{4} @ \mathrm{SiO}_{2}$, and (c) $\mathrm{Fe}_{3} \mathrm{O}_{4} @ \mathrm{SiO}_{2}$ nanocomposites; (a, inset) expanded region of the $\mathrm{N} 1 \mathrm{~s}$ peak at $\sim 400 \mathrm{eV}$, indicating the presence of azide groups. 


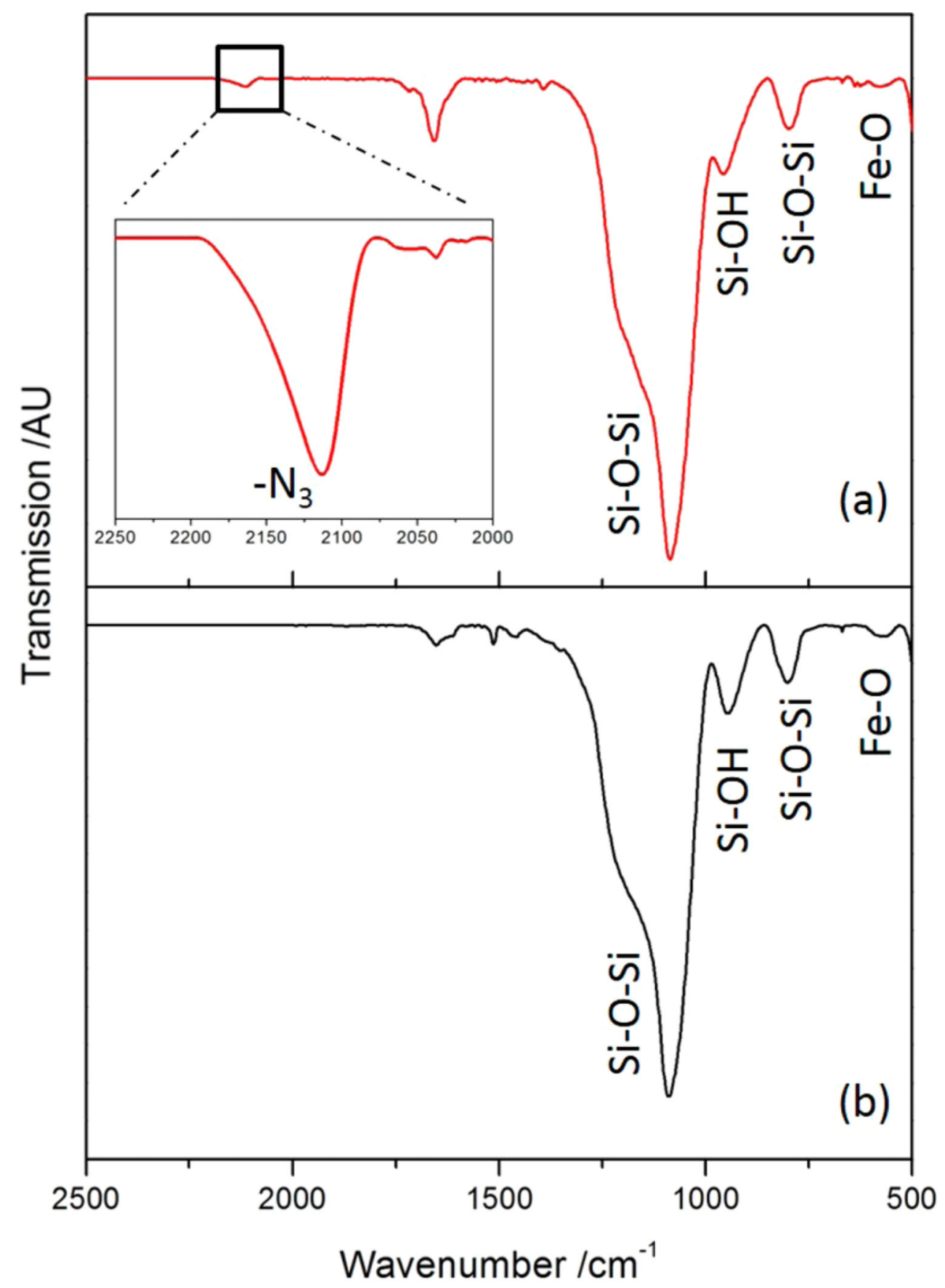

Figure 7.

FTIR spectra of (a) $\mathrm{Fe}_{3} \mathrm{O}_{4} @ \mathrm{SiO}_{2}$-azide and (b) $\mathrm{Fe}_{3} \mathrm{O}_{4} @ \mathrm{SiO}_{2}$ nanoparticles. (a, inset)

Expanded region around $2100 \mathrm{~cm}^{-1}$, indicating the presence of azide groups on the particle surface. 


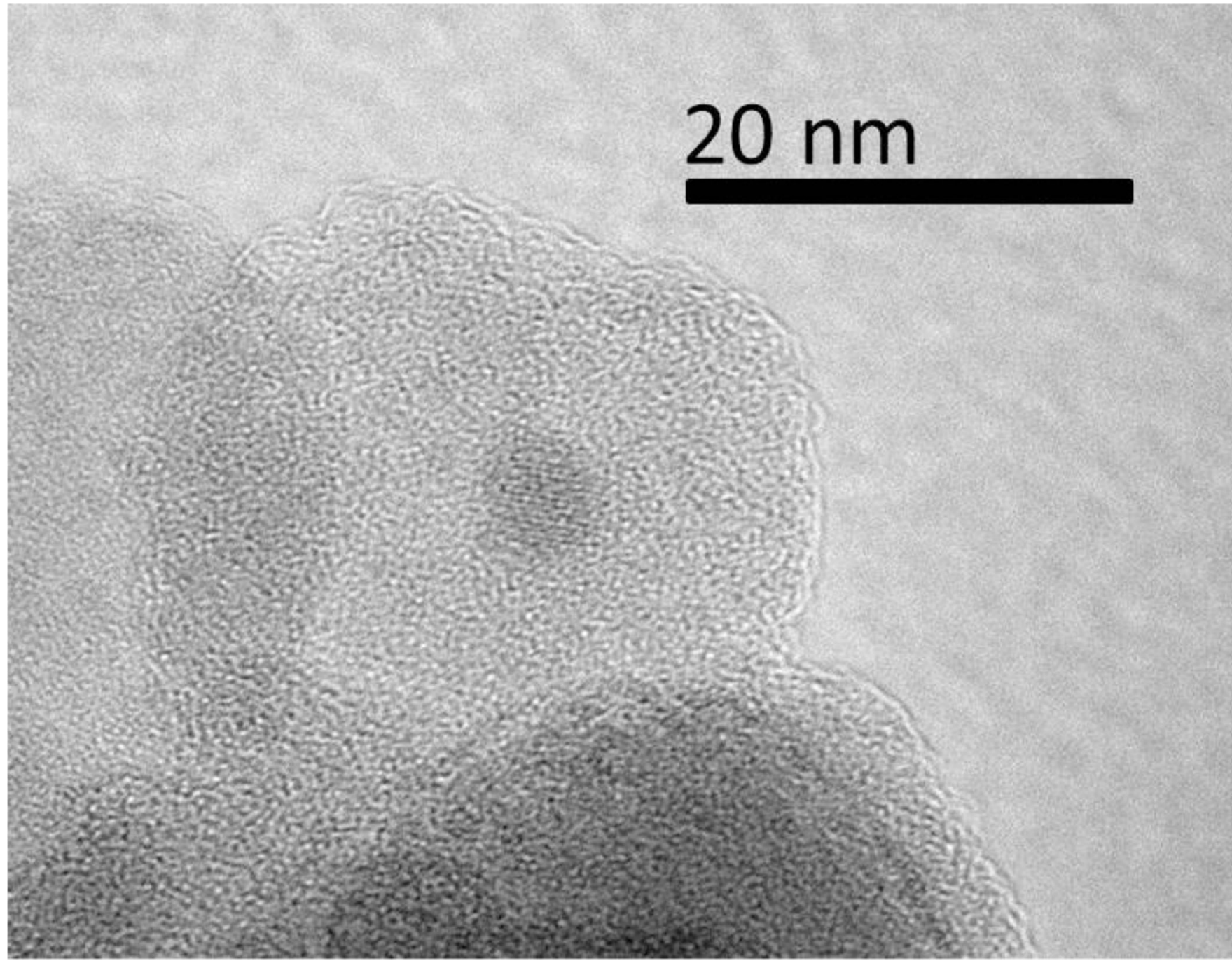

Figure 8.

TEM image of silica- $\mathrm{Fe}_{3} \mathrm{O}_{4}$-click-ZnTPP nanoparticles. 


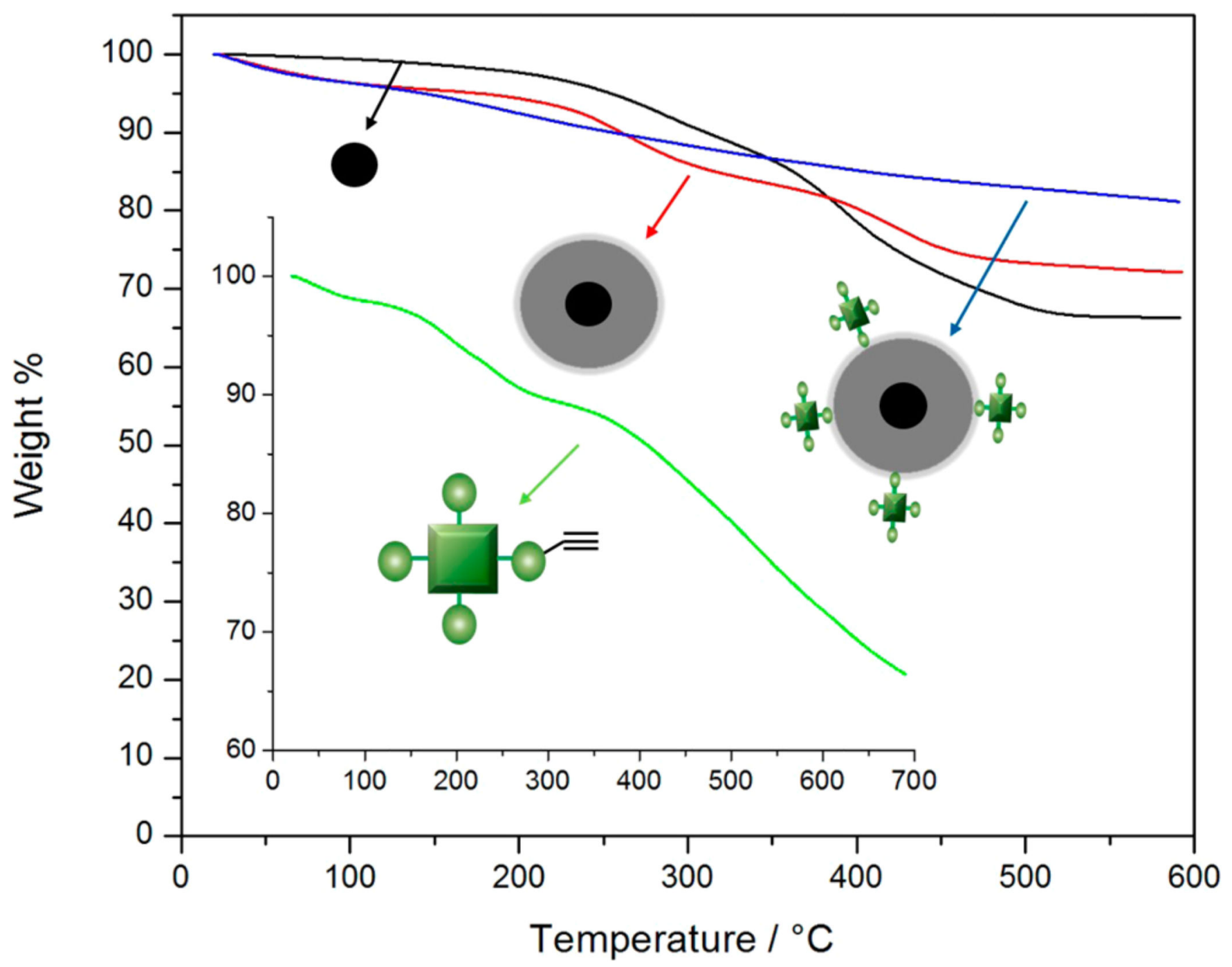

Figure 9.

TGA curves for (black) iron oxide $\left(\mathrm{Fe}_{3} \mathrm{O}_{4}\right)$, (red) silica-coated $\mathrm{Fe}_{3} \mathrm{O}_{4}$, and (blue) silica$\mathrm{Fe}_{3} \mathrm{O}_{4}$-click-metalloporphyrin nanoparticles; (inset, green) shows the TGA curve of alkynemetalloporphyrin. 

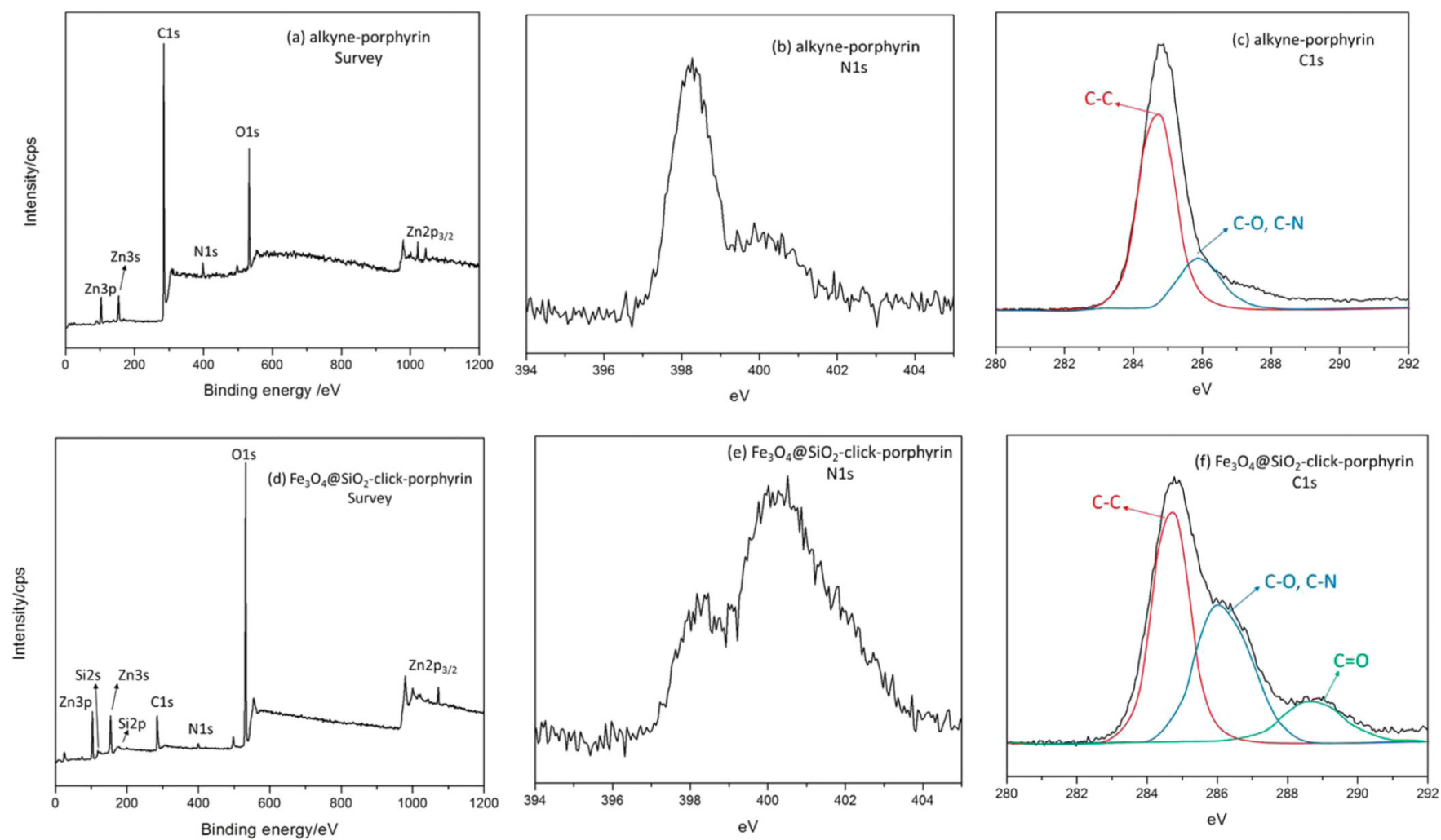

Figure 10.

(a) XPS survey scan of alkyne-ZnTPP. High-resolution scan ofN1s and C 1s peaks of (b, c) alkyne-ZnTPP, respectively. (d) XPS survey scan of $\mathrm{Fe}_{3} \mathrm{O}_{4} @ \mathrm{SiO}_{2}$-click-ZnTPP. Highresolution scan of $\mathrm{N} 1 \mathrm{~s}$ and $\mathrm{C}$ 1s peaks of $(\mathrm{e}, \mathrm{f}) \mathrm{Fe}_{3} \mathrm{O}_{4} @ \mathrm{SiO}_{2}$-click-ZnTPP, respectively. 


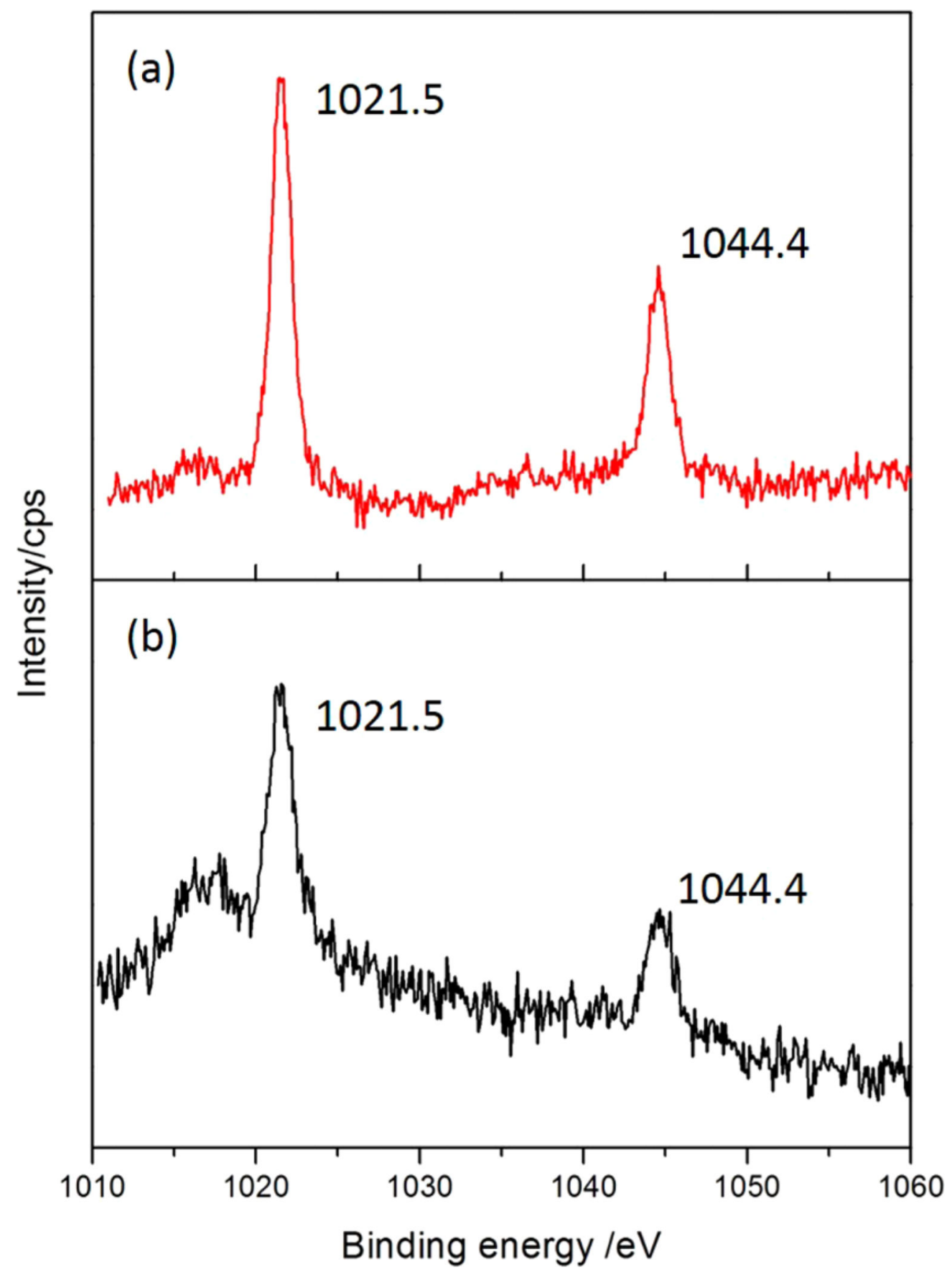

Figure 11.

High-resolution scan of $\mathrm{Zn} 2 p$ peaks of (a) alkyne-ZnTPP and (b) silica-Fe $\mathrm{O}_{4}$-click-ZnTPP nanoparticles. 


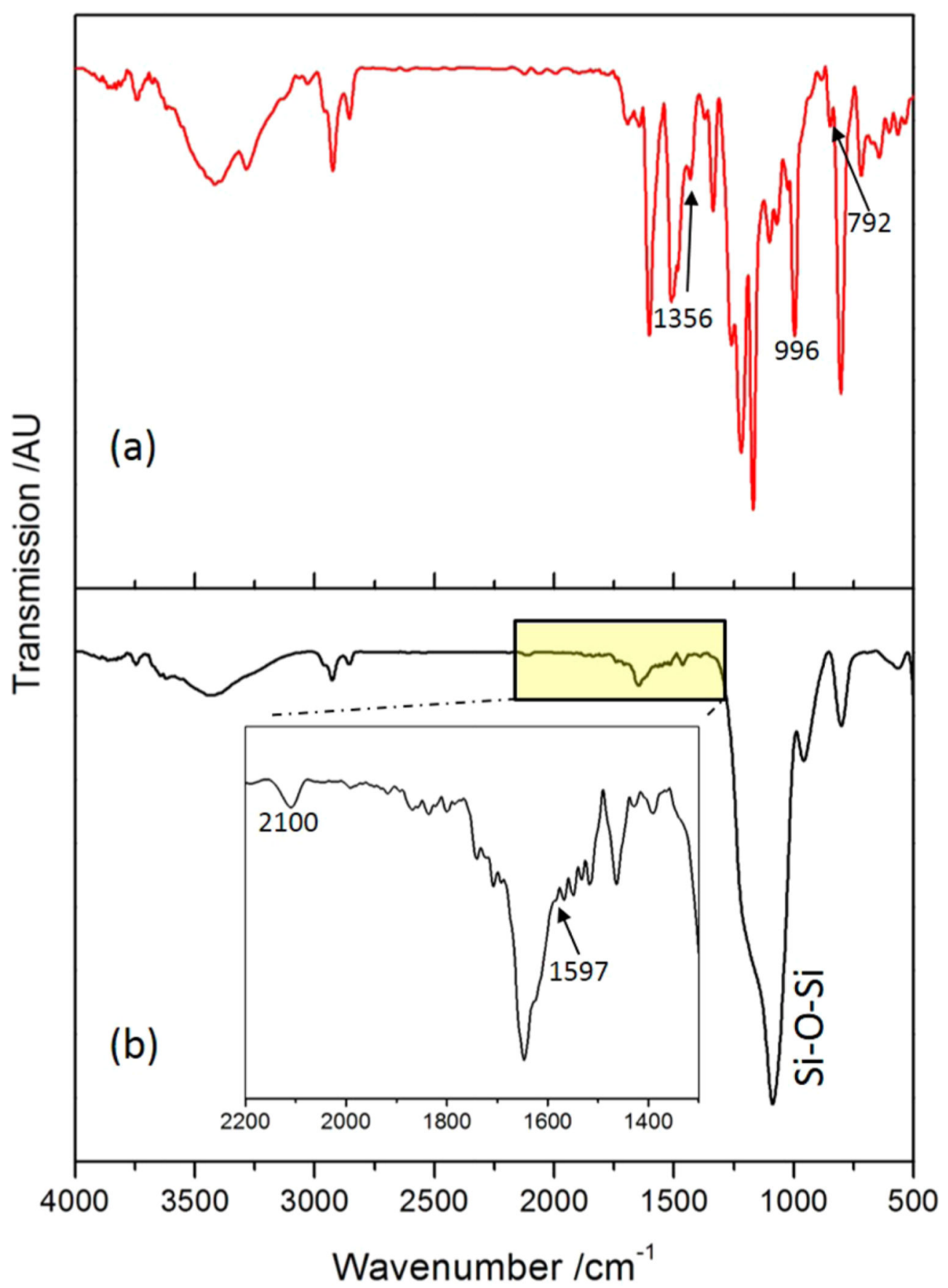

Figure 12.

FTIR spectra of (a) alkyne-ZnTPP and (b) silica-Fe ${ }_{3} \mathrm{O}_{4}$-click- ZnTPP nanoparticles; (b, inset) an expansion of the highlighted region in the spectrum of silica- $\mathrm{Fe}_{3} \mathrm{O}_{4}$-click-ZnTPP, which indicates the reaction of azide groups and attachment of ZnTPP. 
Hollingsworth et al.
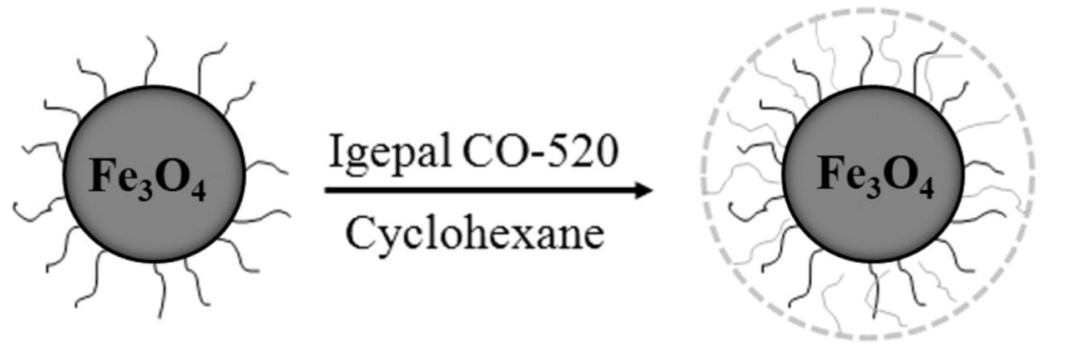

\section{$\underset{\text { 1. } \mathrm{NH}_{3} \cdot \mathrm{H}_{2} \mathrm{O}}{\stackrel{\text { TEOS }}{\longrightarrow}}$}

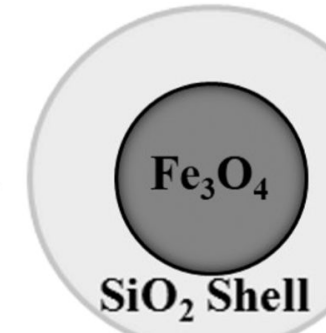

Scheme 1.

Synthesis of Silica-Coated $\mathrm{Fe}_{3} \mathrm{O}_{4}$ Nanoparticles via the Microemulsion Procedure 

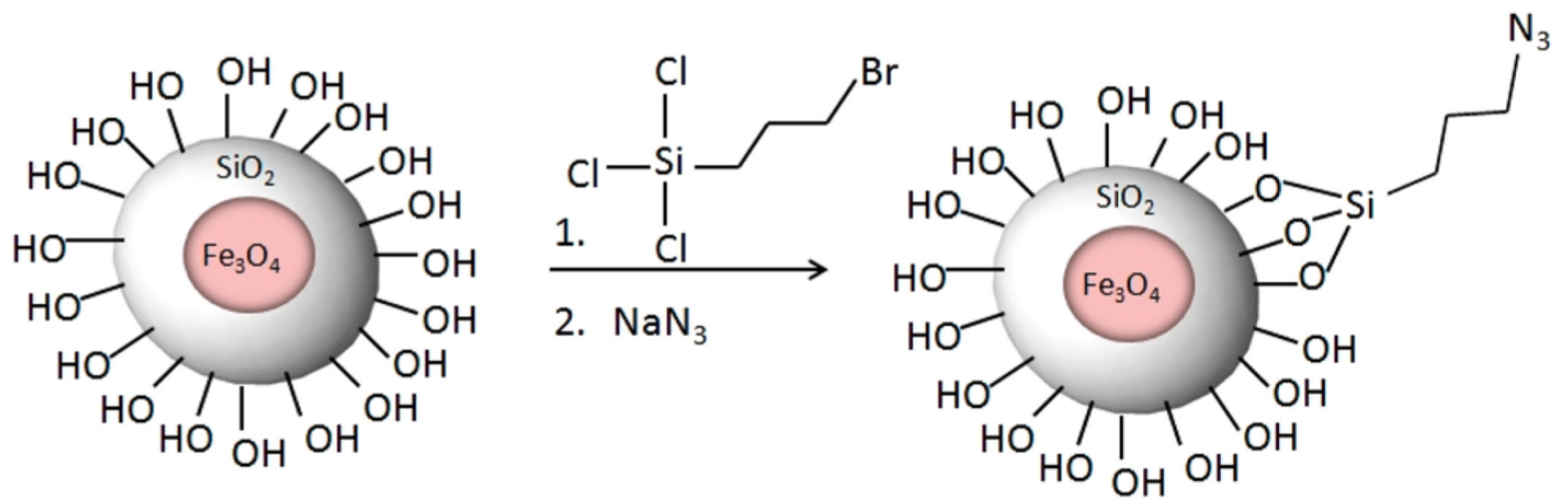

Scheme 2.

Schematic Representation of the Preparation and Azido-Functionalization of $\mathrm{Fe}_{3} \mathrm{O}_{4} @ \mathrm{SiO}_{2}$ Nanoparticles 
<smiles></smiles>

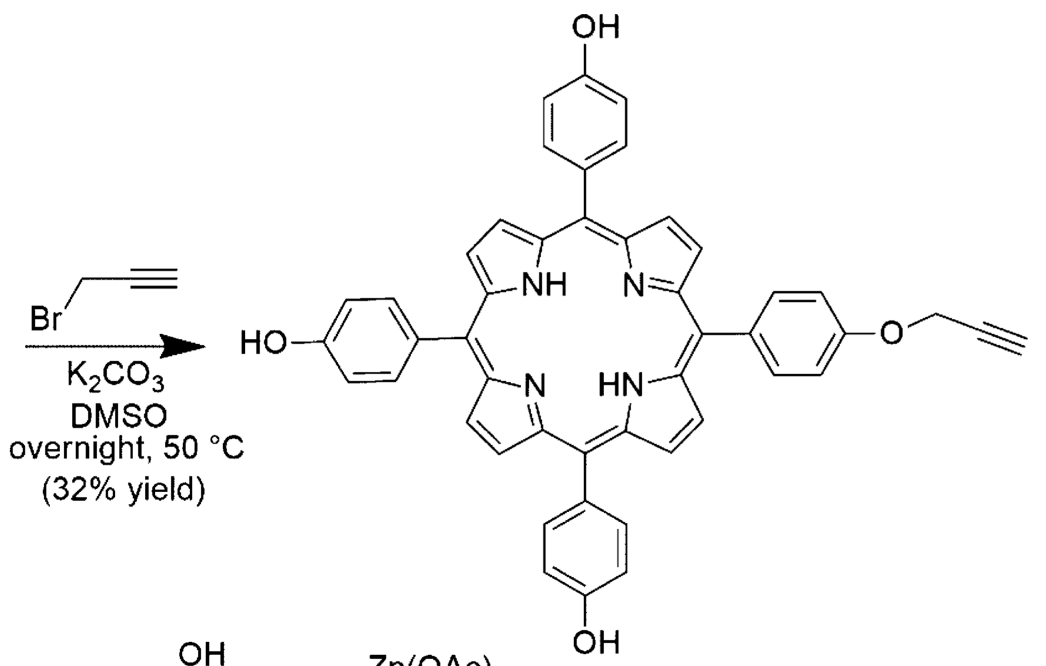

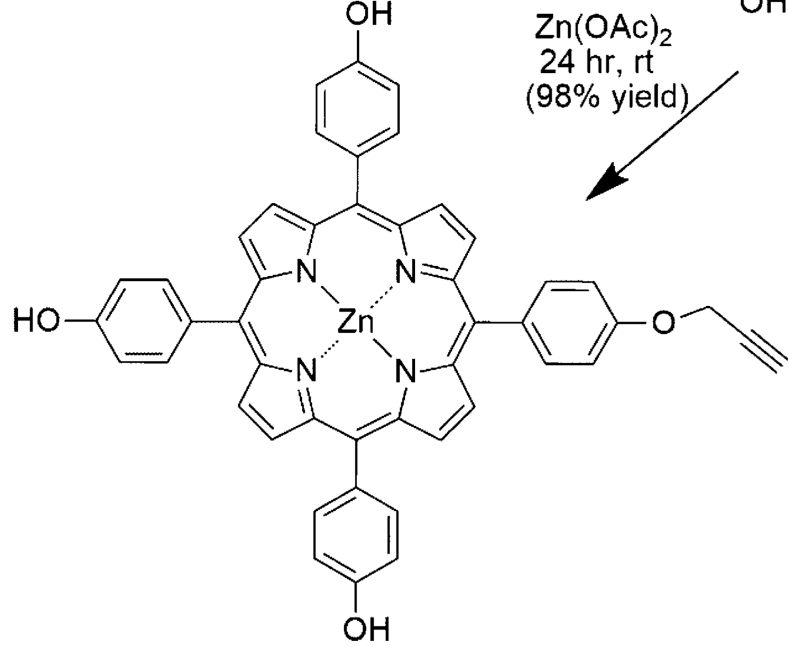

Scheme 3.

Reaction Conditions for the Synthesis of Propargyl-Terminated Zn-Porphyrin 

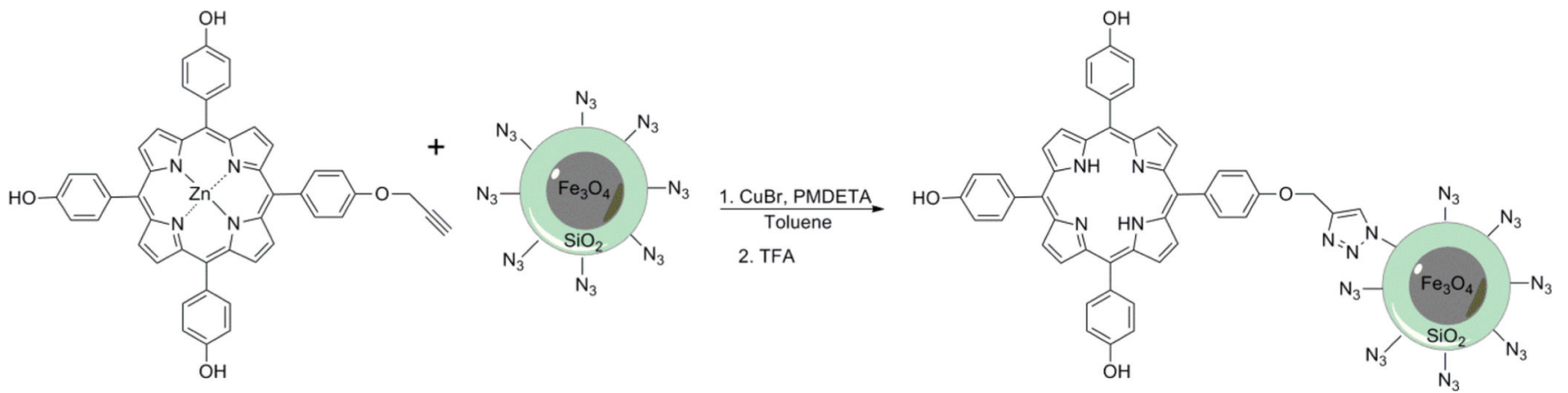

Scheme 4.

Schematic Representation of Click Immobilization of Mono-Alkyne Metalloporphyrin onto Azido-Functionalized Magnetic Silica-Coated Nanoparticles, Followed by Demetallation to Obtain the Free-Base Porphyrin Conjugate 